\title{
Impact of Gastric Acid Induced Surface Changes on Mechanical Behavior and Optical Characteristics of Dental Ceramics
}

Aditi Kulkarni

Nova Southeastern University

Follow this and additional works at: https://nsuworks.nova.edu/hpd_cdm_stuetd

Part of the Dentistry Commons

All rights reserved. This publication is intended for use solely by faculty, students, and staff of Nova Southeastern University. No part of this publication may be reproduced, distributed, or transmitted in any form or by any means, now known or later developed, including but not limited to photocopying, recording, or other electronic or mechanical methods, without the prior written permission of the author or the publisher.

\section{NSUWorks Citation}

Aditi Kulkarni. 2016. Impact of Gastric Acid Induced Surface Changes on Mechanical Behavior and Optical Characteristics of Dental Ceramics. Master's thesis. Nova Southeastern University. Retrieved from NSUWorks, College of Dental Medicine. (112)

https://nsuworks.nova.edu/hpd_cdm_stuetd/112.

This Thesis is brought to you by the College of Dental Medicine at NSUWorks. It has been accepted for inclusion in Student Theses, Dissertations and Capstones by an authorized administrator of NSUWorks. For more information, please contact nsuworks@nova.edu. 
IMPACT OF GASTRIC ACID INDUCED SURFACE CHANGES ON MECHANICAL BEHAVIOR AND OPTICAL CHARACTERISTICS OF DENTAL CERAMICS

\author{
ADITI KULKARNI, B.D.S.
}

A Thesis Presented to the Faculty of the College of Dental Medicine of

Nova Southeastern University in Partial Fulfillment of the Requirements for the

Degree of

MASTER OF SCIENCE IN DENTISTRY

July 2016 
(C) Copyright by Aditi Kulkarni 2016 All Rights Reserved 
IMPACT OF GASTRIC ACID INDUCED SURFACE CHANGES ON MECHANICAL BEHAVIOR AND OPTICAL CHARACTERISTICS OF DENTAL CERAMICS

By

ADITI KULKARNI, B.D.S.

A Thesis Submitted to the College of Dental Medicine of Nova Southeastern University in Partial Fulfillment of the Requirements for the Degree of MASTER OF SCIENCE IN DENTISTRY

Department of Prosthodontics

College of Dental Medicine

Nova Southeastern University

July 2016

Approved as to style and content by:

APPROVED BY:

Jeffrey Thompson, B.S. Ph.D. (Committee Chair) Date

APPROVED BY:

Sharon Siegel, D.D.S., M.S., M.B.A, (Committee Member) Date

APPROVED BY:

Rafael G. Castellon, D.D.S., M.S., M.B.A (Committee Member) Date

APPROVED BY:

Carlos Villanueva D.D.S. (Committee Member) Date

APPROVED BY:

Linda Niessen D.M.D., M. P.H. (Dean, College of Dental Medicine) Date 


\section{NOVA SOUTHEASTERN UNIVERSITY}

Health Professions Division

Department of Prosthodontics and Restorative Sciences

College of Dental Medicine

STUDENT NAME: Aditi Kulkarni, B.D.S.

STUDENT E-MAIL ADDRESS: ak880@nova.edu

STUDENT TELEPHONE NUMBER: (317) 476-4010

COURSE DESCRIPTION: Master of Science in Dentistry with specialty certificate in Postgraduate Prosthodontics

TITLE OF SUBMISSION: Impact of gastric acid induced surface changes on mechanical behavior and optical characteristics of dental ceramics

DATE SUBMITED: July 22, 2016

I certify that I am the sole author of this thesis, and that any assistance I received in its preparation has been fully acknowledged and disclosed in the thesis. I have cited any sources from which I used ideas, data, or words, and labeled as quotations any directly quoted phrases or passages, as well as providing proper documentation and citations. This thesis was prepared by me, specifically for the M.Sc.D. degree and for this assignment.

STUDENT

SIGNATURE:

Aditi Kulkarni, B.D.S.

Date 


\section{DEDICATION}

To my loving husband and family for their endless love and support. 


\section{ACKNOWLEDGEMENTS}

I would like to acknowledge the following individuals:

Dr. Jeffrey Thompson for serving as my mentor for this thesis and throughout the Prosthodontics program. Thank you for your patience and guidance throughout this journey.

Dr. Sharon Siegel for serving on my committee. I appreciate all of your assistance and insight during this project.

Dr. Rafael Castellon for serving on my committee. Thank you for all your contributions during this process.

Dr. Carlos Villanueva for serving on my committee. Thank you for your support and guidance.

Mr. James Rothrock for all of his help and insight in the research laboratory. I appreciate your patience and guidance.

Dr. Patrick Hardigan for his guidance and expertise in statistics.

Oral Arts Laboratory, Huntsville, AL for supplying the specimens for the project. Thank you for your creativity and generosity.

Jill Nagler for all her support and efforts. 


\section{ABSTRACT}

\section{IMPACT OF GASTRIC ACID INDUCED SURFACE CHANGES ON MECHANICAL BEHAVIOR AND OPTICAL CHARACTERISTICS OF DENTAL CERAMICS}

DEGREE DATE: JULY 22, 2016

ADITI KULKARNI, B.D.S.

\section{COLLEGE OF DENTAL MEDICINE NOVA SOUTHEASTERN UNIVERSITY}

Thesis Directed By: Jeffrey Thompson B.S., Ph.D., Committee Chair

Sharon Siegel D.D.S., M.S., M.B.A., Committee Member

Rafael Castellon, D.D.S., M.S., M.B.A., Committee Member

Carlos Villanueva, D.D.S., Committee Member

Objective. This study was conducted to test the impact of exposure to artificial gastric acid combined with toothbrush abrasion on the properties of dental ceramics. Earlier research has indicated that immersion in artificial gastric acid has caused increased surface roughness of dental ceramics. However, the combined effect of acid immersion and toothbrush abrasion and the impact of increased surface roughness on mechanical strength and optical properties has not been studied. Methods. Three commercially available ceramics were chosen for this study: feldspathic porcelain, lithium disilicate glass ceramic and monolithic zirconium oxide. The specimens (10×1 mm discs) were cut, thermally treated as required and polished. Each material was divided into four groups ( $n=8$ per group): Control (no exposure), Acid only, Brush only, Acid + Brush. The specimens were immersed in artificial gastric acid $(50 \mathrm{ml}$ of $0.2 \%(\mathrm{w} / \mathrm{v})$ Sodium chloride in $0.7 \%(\mathrm{v} / \mathrm{v})$ Hydrochloric acid mixed with $0.16 \mathrm{~g}$ of pepsin powder, $\mathrm{pH}=2)$ for 2 minutes 
and rinsed with deionized water for 2 minutes. The procedure was repeated 6 times/day x 9 days and specimens were stored in deionized water at $37^{\circ} \mathrm{C}$. Toothbrush abrasion was performed using an ISO/ADA design brushing machine (Sabri Dental Enterprises, Inc.) for 100 cycles/day $\times 9$ days. The Acid + Brush group received both treatments. Specimens were examined under SEM and an optical microscope for morphological changes. Color and translucency were measured using spectrophotometer CIELAB coordinates $\left(L^{*}, a^{*}\right.$ and $\left.b^{*}\right)$; surface gloss was measured using a gloss meter. Surface roughness was measured using a stylus profilometer; biaxial strength was measured using an Instron mechanical testing machine. The data was analyzed by one-way ANOVA followed by Tukey's HSD post hoc test $(p<0.05)$. Results. Statistically significant changes were found for color, gloss and surface roughness for porcelain and E.max samples. No statistically significant changes were found for any properties of zirconia samples. Conclusion. The acid treatment affected the surface roughness, color and gloss of porcelain and E.max ceramics. The changes in translucency and mechanical strength for all materials were not statistically significant. Zirconia ceramic showed resistance to all treatments. 


\section{TABLE OF CONTENTS}

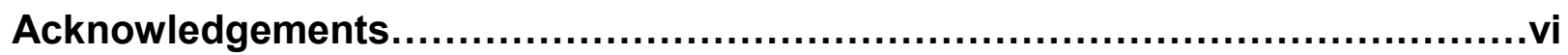

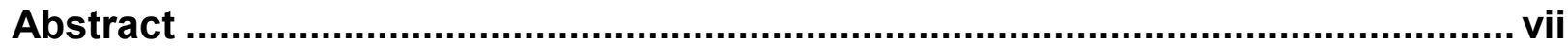

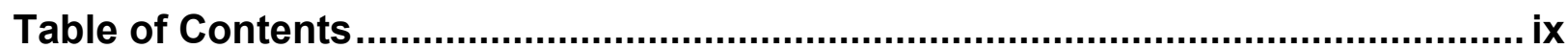

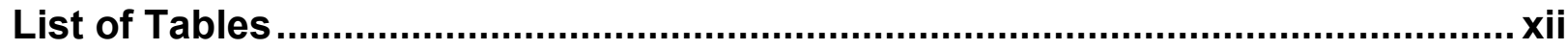

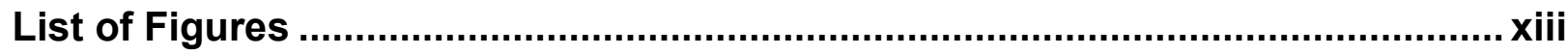

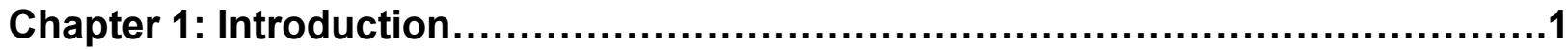

1.1 Prosthodontics and Restorative Dentistry..................................

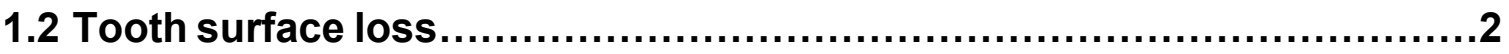

1.2.1 Dental Erosion......................................................

1.3 Gastric reflux disease and Bulimia Nervosa...............................

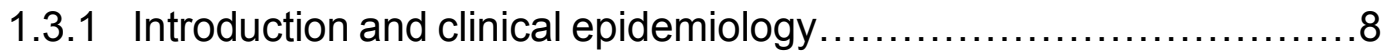

1.3.2 Dental presentation and implications ................................ 8

1.4 Dental Ceramics...................................................................

1.4.1 Evolution of ceramics in dentistry ............................... 10

1.4.2 Desirable properties............................................11

1.4.3 Chemical durability of ceramics in acidic environment..............12

1.5 Purpose, Specific Aims, Hypothesis............................................14

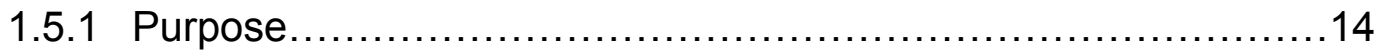

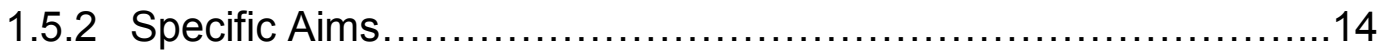

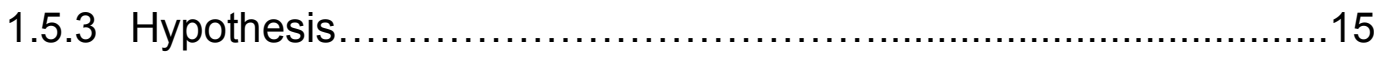

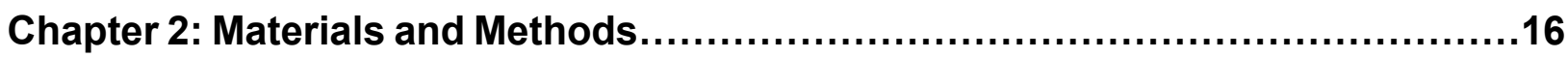

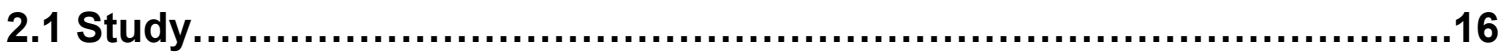

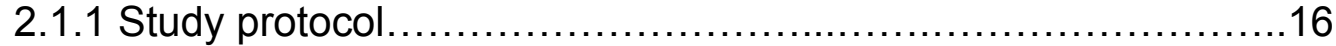


2.1.2 Material selection.

2.1.3 Support acknowledgement...................................17

2.2 Sample Size Estimate......................................................... 18

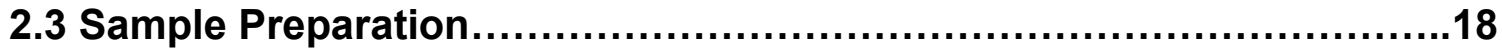

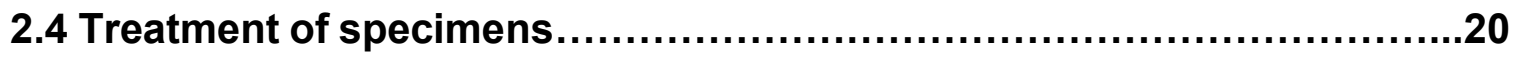

2.4.1 Acid treatment...................................................

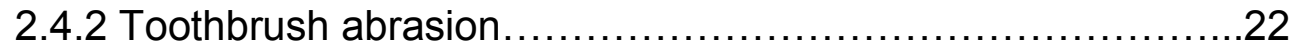

2.5 Morphological assessment of surface topography........................24

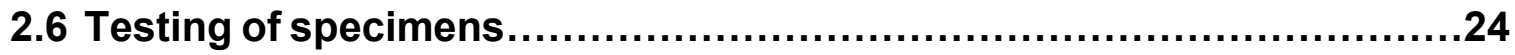

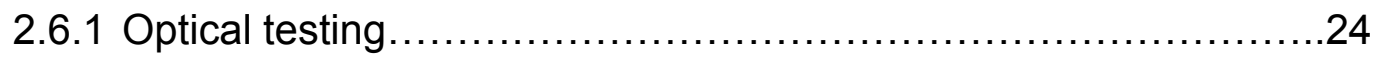

2.6.1.1 Surface gloss measurement..............................24

2.6.1.2 Color and translucency parameter measurement............25

2.6.2 Surface roughness measurement................................27

2.6.3 Biaxial flexural strength measurement............................28

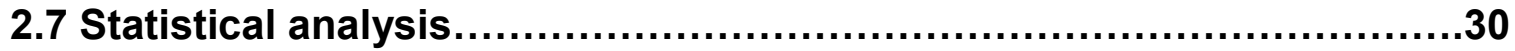

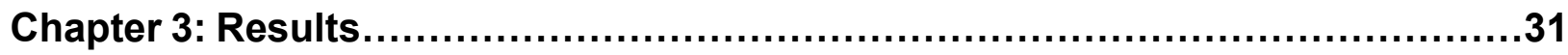

3.1 Surface gloss results........................................................

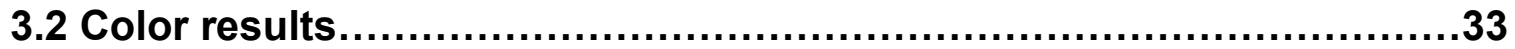

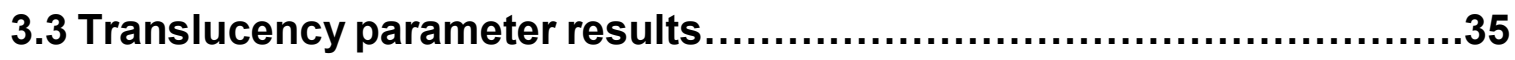

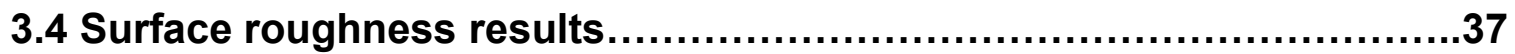

3.5 Biaxial flexural strength results.................................................

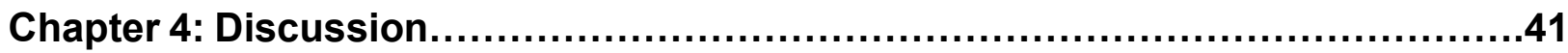

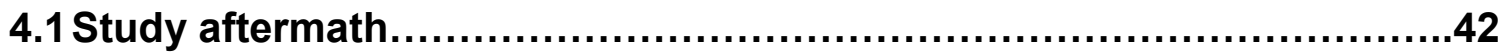

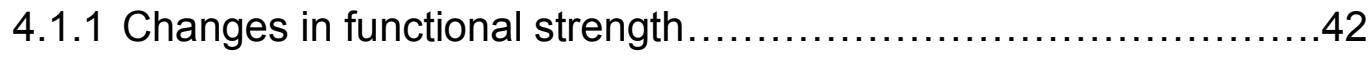

4.1.2 Changes in optical characteristics ...................................44

4.1.2.1 Translucency parameter.................................47

4.1.2.2 Color.................................................... 48

4.1.2.3 Surface gloss.......................................... 50 


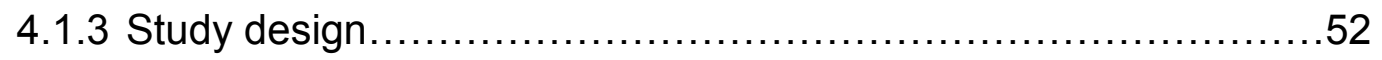

4.2 Morphological assessment of surface characteristics....................55

4.3 Limitations, Implications and Future Studies...............................58

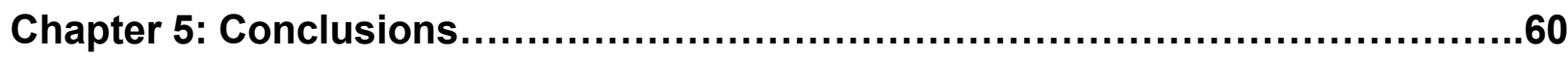

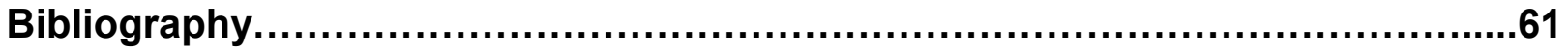




\section{LIST OF TABLES}

Table 1. Intrinsic and Extrinsic causes of dental erosion ................................. 4

Table 2. Eccles and Jenkins Erosion Grading Scale......................................

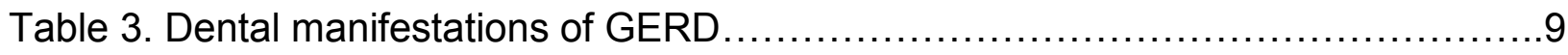

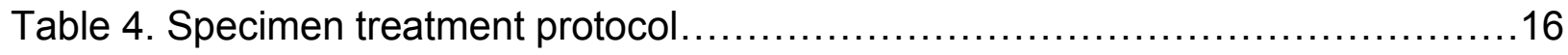

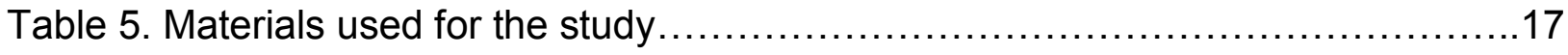

Table 6. Groups based on treatment................................................ 17

Table 7. Descriptive Statistics for Surface gloss .....................................32

Table 8. Descriptive Statistics for Color ..................................................

Table 9. Descriptive statistics for translucency parameter ................................

Table 10. Descriptive statistics for surface roughness.................................38

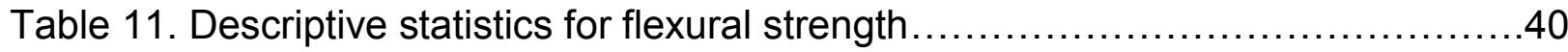




\section{LIST OF FIGURES}

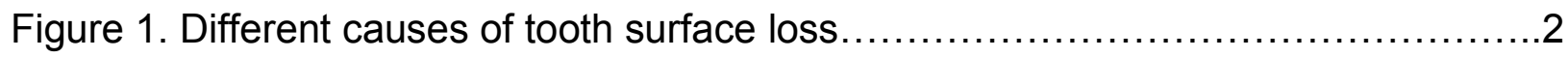

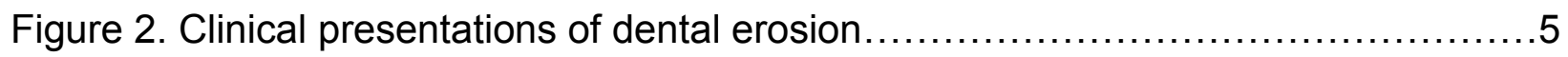

Figure 3. Diagnostic flowchart for dental erosion ......................................

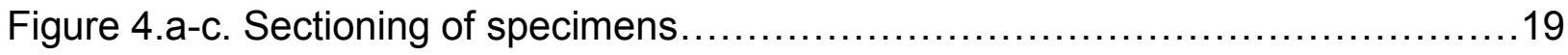

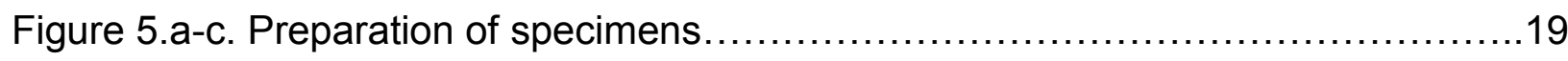

Figure 6.a-b. Preparation of artificial stimulated gastric acid ..........................20

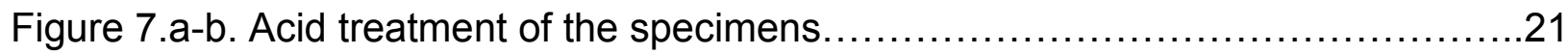

Figure 8.a-b. Tooth brushes and dentifrice as per ADA specifications ...................22

Figure 9.a-e. Tooth brush abrasion of the specimens ................................23

Figure 10.a-b. Surface gloss measurement using glossmeter........................25

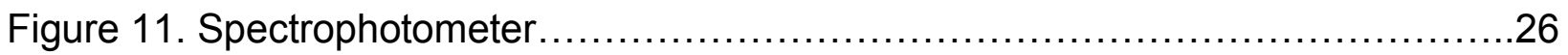

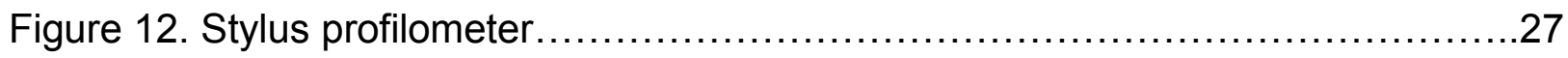

Figure 13. Instron 8871 universal testing machine ...................................29

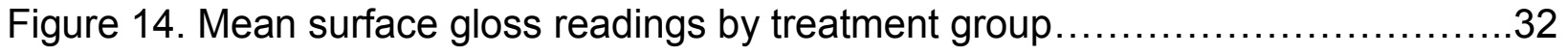

Figure 15. Mean color readings by treatment group ...................................34

Figure 16. Mean translucency parameter readings by treatment group..................36

Figure 17. Mean surface roughness readings by treatment group .....................38

Figure 18. Mean flexural strength readings by treatment group ........................40

Figure 19. $L^{*}, a^{*}$ and $b^{*}$ readings for IPS e.max for different groups...................50

Figure 20. SEM micro graphs of IPS e.max samples of all groups ....................55

Figure 21. SEM micro graphs of Feldspathic porcelain samples of all groups............56 
Figure 22. SEM micro graphs of Monolithic zirconia samples of all groups.............57 


\section{CHAPTER 1: INTRODUCTION}

\subsection{Prosthodontics and restorative dentistry}

The specialty of Prosthodontics was second to Oral Surgery to appear as a dental specialty, and is recognized as an adaptable and innovative branch of dentistry, evolved to manage more sophisticated patient needs and embrace new technologies ${ }^{1}$. There is a rise in the elderly population in industrialized countries leading to distinct oral health problems, including but not limited to those affecting restorative dentistry such as root caries or dental erosion, of which the prevalence seems to be on the rise ${ }^{2-3}$. In keeping with increasing demands in oral health, dental research has invested a great deal in development of state of the art dental materials. Restorative dentistry has undergone significant advances in therapeutic modalities to manage complex dental conditions ${ }^{4}$. The goal of any dental rehabilitation is to restore health, function and esthetics. In addition, the durability and predictability of interceptive dental treatment is an important factor in the decision making process. There seems to be a paradigm shift towards metal-free ceramic restorations in modern day clinical dentistry due to the significant improvement in the mechanical and optical properties of this class of materials. This has made it possible to accomplish comprehensive dental reconstructions which are esthetically superior and meet functional requirements. As a specialty, Prosthodontics has always been at the cutting edge of technological progressions. In today's world, since patients have easy access to exploring treatment options, there is an increased awareness among the population about seeking dental therapy. 


\subsection{Tooth surface loss}

Wear is defined as deterioration as a result of use ${ }^{5}$ and the term was first used by Hunter in Dentistry 6 . Tooth surface loss occurs due to a variety of causes listed in the Figure 1.

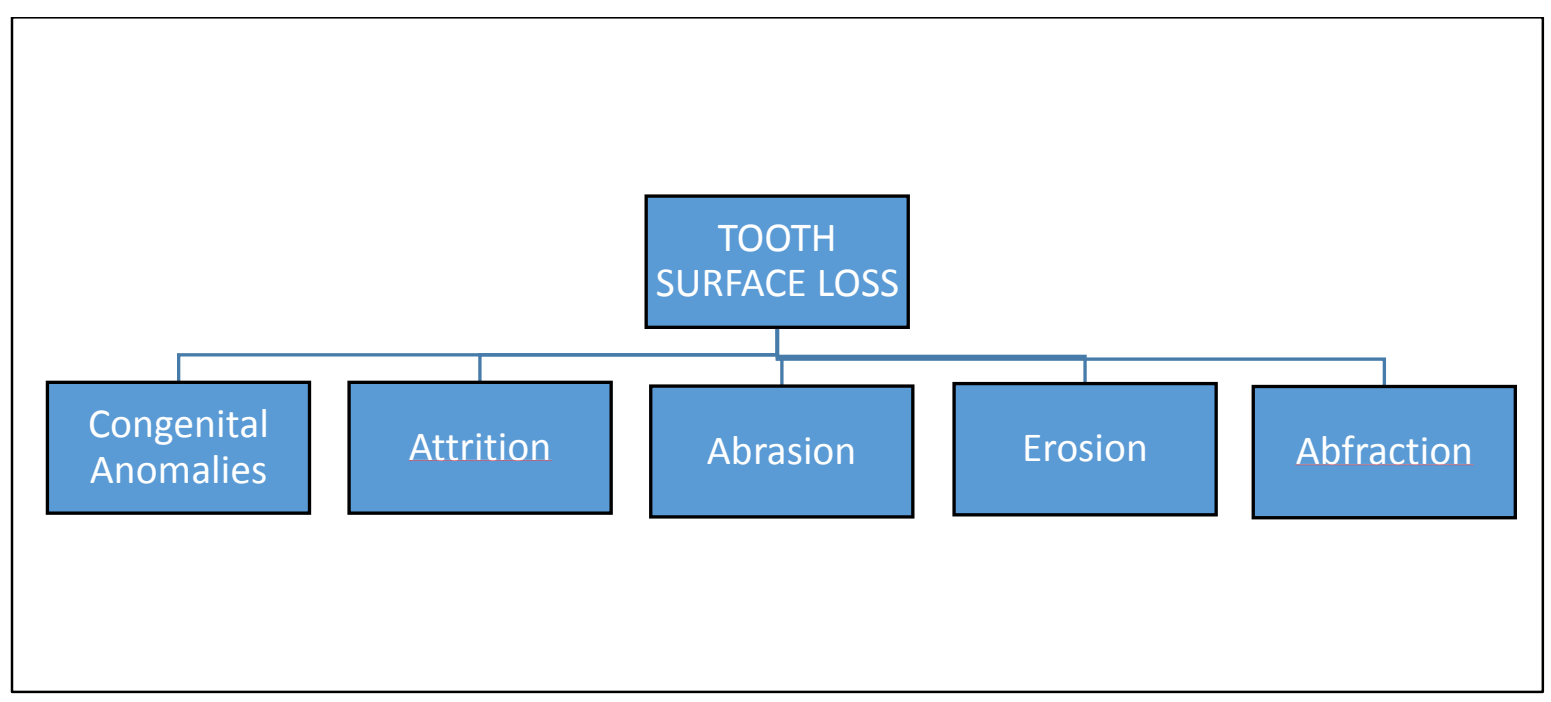

Figure 1. Different causes of tooth surface loss

Tooth wear can also be broadly categorized based on its etiology as occurring due to mechanical, chemical or biomechanical causes. ${ }^{7}$

Attrition is defined as the mechanical wear resulting from mastication or parafunction limited to contacting surfaces of teeth. ${ }^{8}$ Physiologic wear of contacting surfaces of teeth is a normal occurrence during the lifetime of an individual. ${ }^{9}$ Patients often report no symptoms and lesions can be clearly identified on the occluding surfaces of the teeth as small polished facets on the cusp or ridge or a slight flattening of an incisal edge. ${ }^{10}$ Reports have indicated that estimated tooth loss due to wear of enamel is approximately $65 \mu \mathrm{m} /$ year. ${ }^{11}$ 
Abrasion is defined as the abnormal wearing of tooth substance by causes other than mastication. This type of wear is caused due to foreign objects or substances continuously rubbing against tooth surfaces. For example, aggressive tooth brushing with abrasive dentifrices, damaging habits such as opening hair pins with teeth or biting nails, tacks, pins, thread, a pipe stem, or a wind instrument. ${ }^{10}$ Each of the mentioned substances/objects produce a characteristic pattern of wear and is a valuable diagnostic parameter.

Abfraction is the abnormal loss of tooth substance caused by biomechanical loading factors. The lesions present themselves as wedge-shaped defects at the cervical areas of the teeth and their etiopathology remains controversial. ${ }^{12-13}$

Congenital abnormalities like Amelogenesis Imperfecta and Dentinogenesis Imperfecta can also cause loss of tooth structure with very peculiar clinical presentations. These abnormalities are shown to accelerate other forms of tooth wear due to decreased wear resistance and weakening of the tooth structure. ${ }^{14}$ An understanding of the etiological factors is essential to differentiate these forms of wear from dental erosion, which is caused due to chemical factors.

\subsubsection{Dental Erosion}

The Glossary of Prosthodontic Terms defines erosion as the progressive loss of tooth substance by chemical processes that do not involve bacterial action producing defects that are sharply defined wedge-shaped depressions, often in facial and cervical areas. There are increasing number of reports in the literature suggesting that dental erosion is a major cause of dental wear, surpassing wear 
dueto attrition or abrasion. ${ }^{15-17}$ Chemical insults to the teeth seem to cause the most accelerated tooth loss leading to severe damage within a considerably short period of time. There has been growing awareness about this condition during the last few decades. ${ }^{7}$ The clinical presentation of the lesions varies according to the causative factors, which can be either intrinsic or extrinsic. Table 1 summarizes the intrinsic and extrinsic causes of dental erosion. ${ }^{18}$

\begin{tabular}{|c|c|c|}
\hline & EXTRINSIC & INTRINSIC \\
\hline 1 & $\begin{array}{c}\text { Carbonated beverages, acidic } \\
\text { foods, citric lozenges, medications }\end{array}$ & Bulimia Nervosa \\
\hline 2 & $\begin{array}{c}\text { Oral hygiene swab sticks, saliva } \\
\text { substitutes }\end{array}$ & Voluntary reflux phenomenon \\
\hline 3 & Gas-chlorinated swimming pools & $\begin{array}{c}\text { Subclinical regurgitation due to } \\
\text { chronic gastritis associated with } \\
\text { alcoholism }\end{array}$ \\
\hline 4 & $\begin{array}{c}\text { Occupational exposure to corrosive } \\
\text { agents }\end{array}$ & Malabsorption syndrome \\
\hline 5 & & Chronic vomiting during pregnancy \\
\hline 6 & & Gastro-esophageal reflux \\
\hline
\end{tabular}

Table 1. Intrinsic and Extrinsic causes of dental erosion ${ }^{18}$

Identification of clinical lesions is imperative to confirmation of the diagnosis of the lesions. Clinically, the enamel exhibits a smooth, glazy appearance, without anatomical ridges or grooves. Lesions involving dentin exhibit a more dull appearance, and in posterior teeth, islands of restorations project toward the occlusal aspect. Incisal edges or anterior teeth and cusps of posterior teeth exhibit 
a "cupped" appearance. Extrinsic factors most commonly affect the labial surfaces of anterior teeth and intrinsic factors like chronic vomiting disorders or silent regurgitation affect palatal aspects of maxillary anterior teeth. ${ }^{7}$ The persistent vomiting in anorexia nervosa and bulimia sufferers has the potential to lead to detrimental oral complications, including perimolysis, cervical caries, tooth sensitivity, impairment of mucous membrane, periodontopathy, glossodynia, xerostomia, enlargement of the parotid glands, halitosis, taste impairment, mouth ulcers, and sore throat. ${ }^{19-21}$ Examples of lesions are shown in Figure 2.

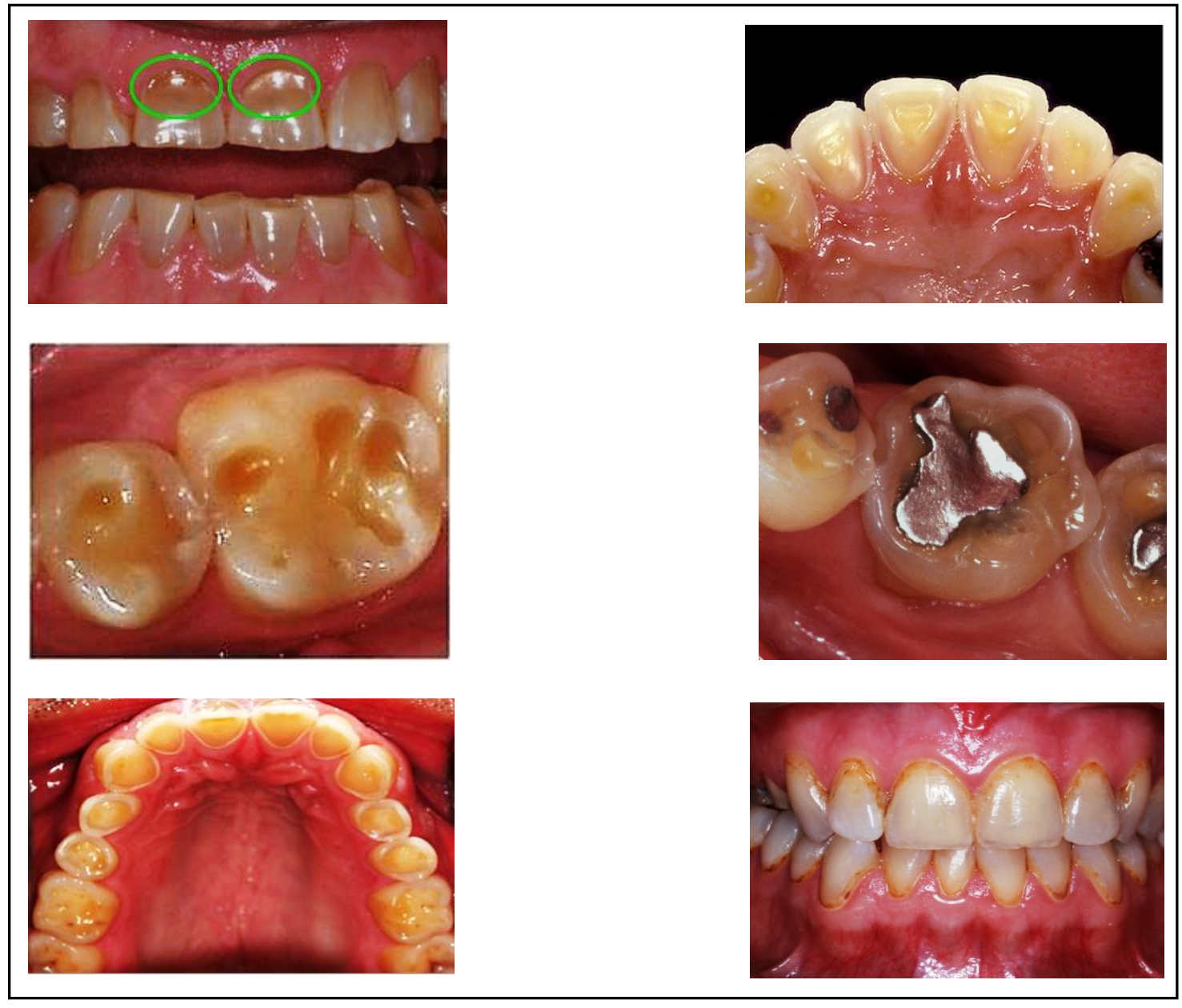

Figure 2. Clinical presentations of dental erosion 
The diagnostic parameters for different causes of chemical erosion and their possible causes can be summarized in Figure 3 (Adapted from Verrett, 2001). ${ }^{7}$

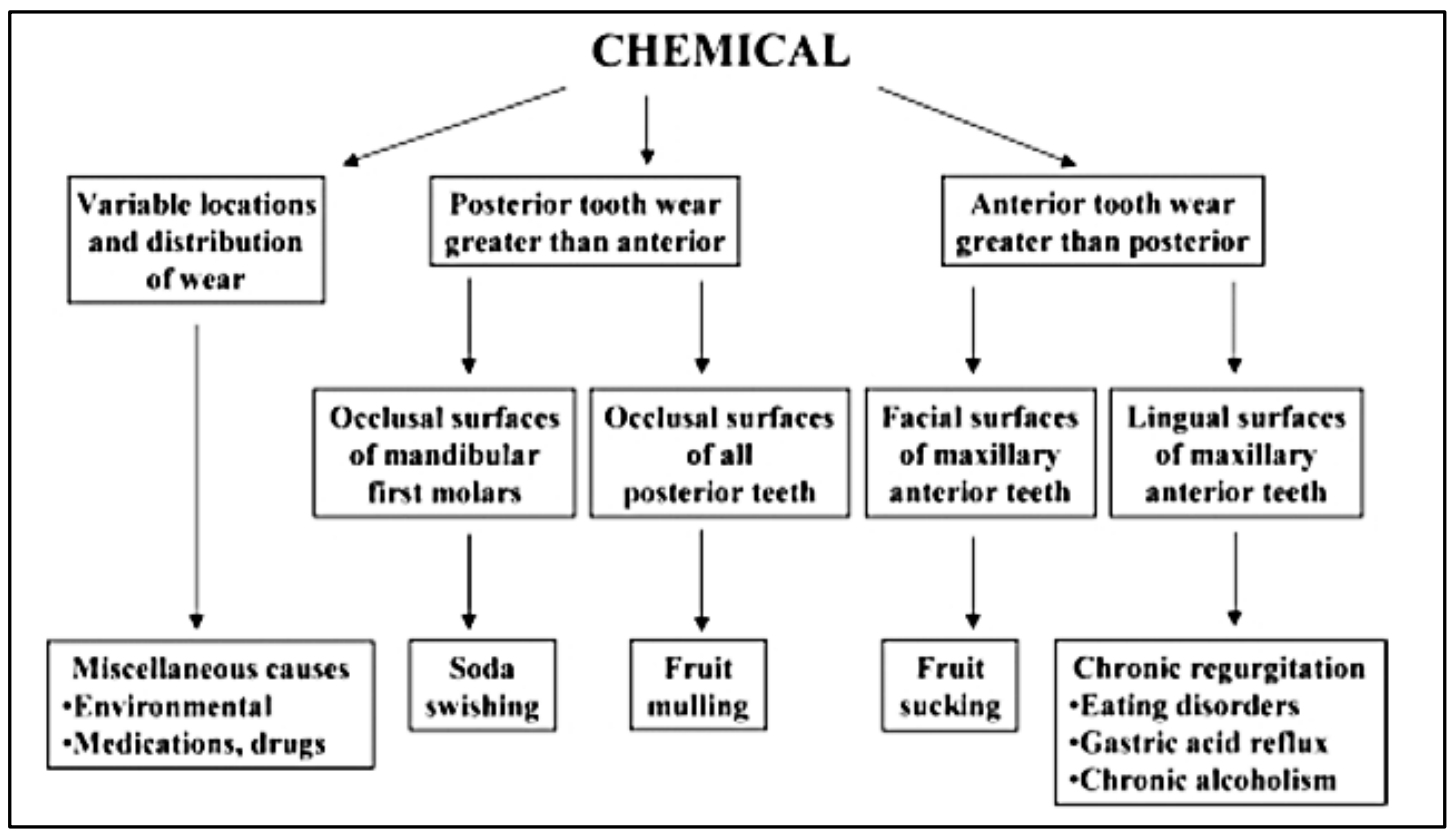

Figure 3. Diagnostic flowchart for dental erosion ${ }^{7}$

Presence of dental erosion is particularly detrimental to the dentition because it is known to potentiate other forms of mechanical wear by weakening the intermolecular bonds of the surface. ${ }^{5,22}$ The gradient of mineral loss as the result of softening of eroded enamel thins the external layer of the mineral crystal, thus making it more susceptible to mechanical abrasion. ${ }^{23,}{ }^{24}$ This finding is confirmed by numerous experimental studies. In an attempt to have an effective treatment strategy, various diagnostic indices have been developed in an attempt to quantitatively assess the amount of loss of tooth structure..$^{25}$ One such example is demonstrated in Table 2, adapted from Eccles and Jenkins. ${ }^{26}$ 


\begin{tabular}{|c|c|}
\hline RATING & SEVERITY OF EROSION \\
\hline GRADE 0 & No involvement of surface \\
\hline GRADE 1 & Loss of enamel surface; no dentin involvement \\
\hline GRADE 2 & Exposure of dentin on less than $1 / 3$ of surface \\
\hline GRADE 3 & Exposure of dentin on more than $1 / 3$ of surface \\
\hline
\end{tabular}

Table 2. Eccles and Jenkins Erosion Grading Scale ${ }^{26}$

It is evident that dental wear seems to be a complex multifactorial process, requiring precise knowledge of the different processes contributing to the etiology to be able to comprehensively manage the conditions and rehabilitate the dentition. 


\subsection{Gastric reflux disease and Bulimia Nervosa}

\subsubsection{Introduction and clinical epidemiology}

The term gastro-esophageal reflux disease (GERD) is used to describe the symptoms and changes of the esophageal mucosa that result from reflux of stomach contents into the esophagus. ${ }^{27}$ Gastro-esophageal reflux disease is a fairly common medical condition. $15 \%$ individuals experience heartburn once a week; $7-10 \%$ individuals experience heart burn once daily; $25-40 \%$ of Americans experience symptomatic GERD at some point; $45 \%-85 \%$ of women during pregnancy experience GERD or heart burn. ${ }^{28-29}$ Bulimia nervosa is an eating disorder characterized by self-induced vomiting ${ }^{30}$ and is seen to impair physical well-being and psychosocial functioning ${ }^{31}$. Both medical conditions cause gastric acid to accumulate in the oral cavity for variable periods of time, leading to destructive effects on the dentition as described in previous sections. There are many open questions about etiology of GERD.${ }^{27}$ Severe exposure of teeth to acid is particularly common in subjects with eating disorders, as vomiting frequencies of 6-10 times per day are often reported from patients, many of whom vomit for several hours each day. ${ }^{32-33}$

\subsubsection{Dental presentation and implications}

The first association between GERD and dental erosion was reported in 1933. ${ }^{34}$ It has been shown that there is a 31 times higher incidence of acid erosion of teeth in patients with GERD compared to controls. ${ }^{35}$ A case-control study conducted by Johansson et al ${ }^{36}$, showed a significant correlation between eating disorders like 
bulimia nervosa and dental erosion. This study also demonstrated erosion was significantly worse in individuals with longer duration of the disease. It has been well established, that presence of acid in the oral cavity has destructive effects on the dentition ${ }^{37}$ due to its high erosive potential. ${ }^{38}$ The overall dental considerations of GERD include dysgeusia, dental sensitivity, dental erosion, pulpitis, fibrosis and other mucosal changes. ${ }^{39}$ The oral manifestations of GERD can be summarized in Table 3. (Adapted from Barron et al)..$^{25}$

\section{ORAL MANIFESTATIONS OF GERD}

Burning mouth sensation

Tongue sensitivity

Nonspecific itching/burning

Tooth erosion

Dentinal hypersensitivity

Loss of vertical dimension of occlusion

Esthetic disfigurement

Table 3. Dental manifestations of GERD ${ }^{25}$ 


\subsection{Dental ceramics}

\subsubsection{Evolution of ceramics in dentistry}

Research on ceramics began as early as the $1700 \mathrm{~s}^{40}$ and materials have greatly evolved over the years. Currently available dental ceramics have been classified as predominantly glassy materials, particle-filled glass and polycrystalline ceramics. $^{41-44}$ Each class differs in mechanical properties and optical characteristics and hence have different indications for use. Feldspathic porcelain is a predominantly glassy ceramic which belongs to the family of aluminosilicate glass ${ }^{43}$ and has an amorphous three-dimensional structure of atoms. This class of ceramics has the closest match to the optical properties of enamel and dentin. ${ }^{41}$ The first porcelain crown was introduced by Lang ${ }^{45}$, and has been used with modifications in structure ever since as a veneering material for metal substructures, onlays, inlays and veneers ${ }^{41}$. In the 1960 s, Mclean initiated the idea of adding aluminum oxide to feldspathic porcelain to improve its mechanical and physical properties ${ }^{46}$ Modifications included addition of fillers to overcome several deficiencies including low wear resistance and tensile strength, crack propagation, brittleness ${ }^{47-48}$ These alterations gave birth to the particle-filled glass ceramics which consisted of two or more distinct phases in their structure. Leucite, a crystalline material was the first filler to be added to feldspathic porcelain ${ }^{42-43}$ due to its favorable coefficient of thermal expansion, refractive index which matched that of feldspathic glass and ability to etch it. ${ }^{41} \mathrm{~A}$ higher concentration of leucite was used to obtain a leucite-reinforced glass ceramic (IPS Empress, Ivoclar Vivadent). The successor of this ceramic is a 
lithium disilicate reinforced ceramic (IPS e.max, Ivoclar Vivadent, Schaan, Liechtenstein) which is fabricated by a combination of heat-pressed and lost wax techniques. ${ }^{48}$ It was developed to overcome the low flexural strength of its predecessor, followed by IPS e.max Press (Ivoclar Vivadent) which was introduced in 2005 as an improved press-ceramic material compared to IPS Empress with enhanced optical and physical properties achieved by a modified firing process. ${ }^{49}$ The quest for metal-free restorations with mechanical properties similar to metal lead to the introduction of yttrium-stabilized zirconium oxide in dentistry. Zirconia, which is a crystalline dioxide of zirconium ${ }^{50}$ has a tensile strength of 900-1200 MPa and compressive strength of about $2000 \mathrm{MPa}^{51}$.

\subsubsection{Desirable properties}

Dental ceramics have evolved as the material of choice for restoration of dental hard tissues. They have demonstrated satisfactory clinical longevity ${ }^{52}$ and esthetic characteristics. Ceramics are being increasingly used for metal-ceramic and all ceramic restorations such as inlays, onlays, veneers, full coverage crowns over teeth $^{53}$ and implants and implant abutments. They are known to have very favorable characteristics for use in dentistry such as biocompatibility, resistance to wear and excellent esthetics. ${ }^{54}$ 


\subsubsection{Chemical durability of ceramics in an acidic environment}

Ceramics are considered fairly chemically inert biomaterials ${ }^{55}$, however, due to vast differences in the structure and composition of currently available ceramics, this inertness may not be generalized. ${ }^{54}$ Ceramics used in dentistry are considered chemically stable ${ }^{41}$, however there are concerns about degradation of ceramics in the presence of low or high $\mathrm{pH}$ in the oral cavity. ${ }^{56}$ Newton in 1985 defined durability as the resistance to the attack of glass by water and aqueous solutions. ${ }^{55}$ The possible chemical degradation of ceramics may have effects such as increased abrasion of opposing dental structures, the release of radioactive components, and increased plaque adhesion as a result of wear and chemical attack. ${ }^{56}$ The effect of different acids on ceramic surfaces have been previously studied. ${ }^{54-56}$ It has been seen that on immersion of ceramics in acidic agents for 168 hours, there was in increase in the surface roughness of the ceramics. ${ }^{54}$ There are many implications of increased surface roughness on the mechanical behavior of ceramics, ${ }^{57}$ and corrosion can affect the fracture strength of these materials. ${ }^{57-}$ 58 Surface roughness may potentially affect the strength of the ceramics by possibly altering surface flaws. ${ }^{58}$

Since ceramics are the frontline materials of choice for prosthetic rehabilitations of patients with severe wear, the continued presence of the systemic condition raises concerns about longevity of these materials in patients with chronic GERD. Matsou et al (2011) compared the roughness of three ceramics before and after exposure to simulated vomit solution (SVS) with a $\mathrm{pH}$ of 3.8 using a novel peristaltic pump to simulate periodic acid exposure and concluded that no significant surface 
alterations occurred on ceramics on exposure to stimulated gastric acid. ${ }^{59}$ It has been reported that there is accelerated abrasive wear of CAD-CAM machinable ceramics and veneering ceramics in exposure to acids. ${ }^{60} \mathrm{~A}$ recent study evaluated the effect of gastric acid on monolithic zirconia and found that monolithic zirconia materials show some surface alterations in an acidic environment with minimum effect on their optical properties. ${ }^{61}$ There is a growing interest in the research community to test the durability of ceramics in order to predictably meet patient needs. While ceramics have evolved to demonstrate superior optical and functional properties over the last few decades, the question arises about whether these properties are affected by acidic oral environments.

This study is an attempt to test and quantify the actual effect of changes in surfaces of ceramics when exposed to acid on the functional strength and optical properties. The clinician needs to know the clinical significance of these changes to make informed choices for his/her patients. There is limited literature available to examine the effect of gastric acid induced surface changes of dental ceramics. The current study aims to provide a better understanding to make informed choices for material selection for successfully and predictably rehabilitating a patient with damage caused by eating disorders or GERD. 


\subsection{Purpose, Specific Aims and Hypothesis}

\subsubsection{Purpose}

The objective of this research study is to understand the behavior of dental ceramics in an acidic environment that may exist in patients with GERD or bulimia nervosa. Few existing studies have examined the effect of gastric acid induced surface changes of dental ceramics. Based on previous studies, it is assumed that the exposure of ceramics to gastric acid $(\mathrm{pH}<2)$ causes alterations in their surface texture. However, less is known about the impact of these surface changes on the physical properties of ceramics. The three commercially available dental ceramics that will be used for the study are, feldspathic porcelain, lithium disilicate glass ceramic and monolithic zirconia.

The current study aims to test the hypothesis that exposure to artificial gastric acid combined with toothbrush abrasion will negatively impact the properties of dental ceramics

\subsubsection{Specific Aims}

1) To determine the effect of abrasive wear (using toothbrush abrasion) of ceramics after exposure to artificial gastric acid.

2) To examine the changes in the optical characteristics (color, translucency parameter and surface gloss) of ceramics due to artificial gastric acid and toothbrush abrasion induced surface changes.

3) To examine the changes in functional strength (biaxial flexural strength) of ceramics due to gastric acid and toothbrush abrasion induced surface changes. 


\subsubsection{Hypothesis}

$\mathrm{H}^{\circ}$ - Exposure to gastric acid and toothbrush abrasion will negatively impact the functional strength (biaxial flexural strength) of feldspathic porcelain, lithium disilicate and monolithic zirconia ceramics.

$\mathbf{H}^{\circ}$ - Gastric acid induced surface change will negatively impact the optical characteristics (color, translucency parameter and surface gloss) of feldspathic porcelain, lithium disilicate and monolithic zirconia ceramics. 


\section{CHAPTER 2: MATERIALS AND METHODS}

\subsection{Study}

\subsubsection{Study protocol}

The study protocol was adopted from previous studies on human dentine that studied the cyclic demineralization and remineralization upon exposure to gastric acid and toothbrush abrasion, in an attempt to simulate oral conditions. ${ }^{62-}$

${ }^{63}$ The protocol was modified to incorporate more variables to test the proposed hypothesis. The protocol for the treatment of specimens with acid and toothbrushing was defined (Table 4) prior to dividing specimens into groups.

\begin{tabular}{|c|c|}
\hline $\begin{array}{c}\text { PROTOCOL FOR GASTRIC ACID } \\
\text { TREATMENT }\end{array}$ & $\begin{array}{l}\text { PROTOCOL FOR TOOTH-BRUSH } \\
\text { ABRASION TREATMENT }\end{array}$ \\
\hline $\begin{array}{l}\text { 1. Immersion in stimulated artificial } \\
\text { gastric acid }(\mathrm{pH}=2) \text { for } 2 \text { minutes } \\
\text { 2. Rinsing with distilled water with } 2 \\
\text { minutes }\end{array}$ & $\begin{array}{l}\text { 1. Brushing with a standardized } \\
\text { tooth-brush and dentifrice slurry } \\
\text { using an ISO/ADA design } \\
\text { brushing machine } \\
\text { 2. Brushing force }=4 \mathrm{~N}\end{array}$ \\
\hline $\begin{array}{c}\text { Procedure repeated } 6 \text { times a day } x \\
9 \text { days to simulate } 108 \text { hours of } \\
\text { exposure }\end{array}$ & $\begin{array}{c}\text { Procedure repeated for } 100 \text { cycles } \\
\text { per day for } 9 \text { days }\end{array}$ \\
\hline
\end{tabular}

Table 4. Specimen treatment protocol 


\subsubsection{Material selection}

Three types of dental ceramics were selected for this study, as representative of currently used dental ceramics in a clinical setting, (Table 5). The materials were divided into four groups based on the treatments that they received, summarized in Table 6.

\begin{tabular}{|c|c|c|}
\hline CERAMIC TYPE & PRODUCT & MANUFACTURER \\
\hline $\begin{array}{c}\text { Feldspathic } \\
\text { porcelain }\end{array}$ & VITA VMK 95 & VITA, Zahnfabrik \\
\hline $\begin{array}{c}\text { Lithium disilicate } \\
\text { glass ceramic }\end{array}$ & IPS e. max & $\begin{array}{c}\text { Ivoclar Vivadent, } \\
\text { USA }\end{array}$ \\
\hline Zirconium oxide & $\begin{array}{c}\text { Monolithic } \\
\text { zirconia }\end{array}$ & $\begin{array}{c}\text { Dentsply Cercon, } \\
\text { USA }\end{array}$ \\
\hline
\end{tabular}

Table 5. Materials used for the study

\begin{tabular}{|c|c|c|c|c|}
\hline GROUP & A (n=8) & $B(n=8)$ & $C(n=8)$ & $D(n=8)$ \\
\hline $\begin{array}{c}\text { TREATMENT } \\
\text { OF } \\
\text { SPECIMENS }\end{array}$ & $\begin{array}{c}\text { No } \\
\text { exposure }\end{array}$ & $\begin{array}{c}\text { Exposure } \\
\text { to acid }\end{array}$ & $\begin{array}{c}\text { Exposure } \\
\text { to tooth } \\
\text { brush } \\
\text { abrasion }\end{array}$ & $\begin{array}{c}\text { Exposure } \\
\text { to acid } \\
\text { and tooth } \\
\text { brush } \\
\text { abrasion }\end{array}$ \\
\hline
\end{tabular}

Table 6. Groups based on treatment

\subsubsection{Support Acknowledgement}

This study was awarded a grant by the Health Professions Division at Nova Southeastern University (\#335954). 


\subsection{Sample Size Estimate}

A power estimate indicated an adequate number of samples per group (alpha $=$ 0.05 , power $=80 \%$, standardized effect size of 0.50 ).

\subsection{Sample Preparation}

Three types of dental ceramics were obtained from the manufacturer (Oral Arts Dental Laboratory, Huntsville, Alabama) as pre-sintered milled rods (diameter of 10mm) using Computer-Aided Design/Computer-Aided Manufacturing (CAD/CAM) technology (Figure 4.a). The rods were sectioned (Figure 4.b) using a precision saw (IsoMet $^{\circledR} 1000$ Precision Cutter; Buehler GmbH, Düsseldorf, Germany) at 400 rotations/minute (rpm) to obtain discs with dimensions of $10 \mathrm{x}$ $1 \mathrm{~mm}$ (Figure 4.c). A total of forty-eight specimens were obtained from each material, in order to have eight specimens per group. The specimens were polished under running water (Metaserv ${ }^{\circledR} 2000$ Grinder Polisher; Buehler GmbH, Düsseldorf, Germany) at 300 rotations/minute (rpm) using 400, 600 and 800 -grit silicon carbide paper (3M ESPE, St. Paul, Minn) for 7 minutes each (Figure 5.a-b). The platen size used was $250 \mathrm{~mm}$. The specimens were then ultrasonically cleaned (PC3; L\&R Mfg Co, Kearny, NJ) in distilled water for 15 minutes. Subsequently, the specimens were subjected to heat treatment in a programmed oven (Programat ${ }^{\circledR}$ CS; Ivoclar Vivadent Inc., Figure 5.c), as per recommendations of the manufacturer. Finally, the specimens were divided into 8 per group and immersed in distilled water at $37{ }^{\circ} \mathrm{C}$ (Thermo Scientific Heratherm General Incubator) for 24 hours, in preparation for exposure. 

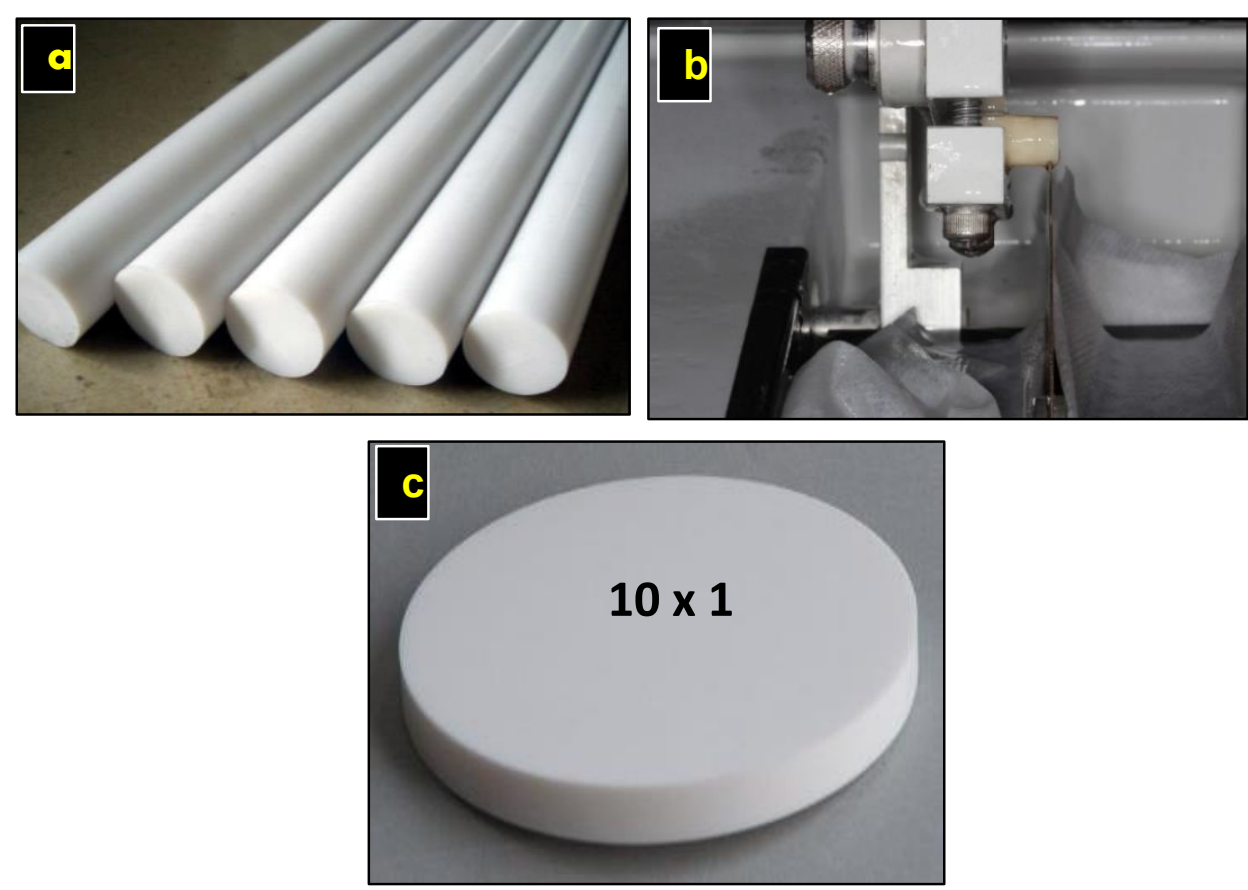

Figure 4.a-c. Sectioning of specimens
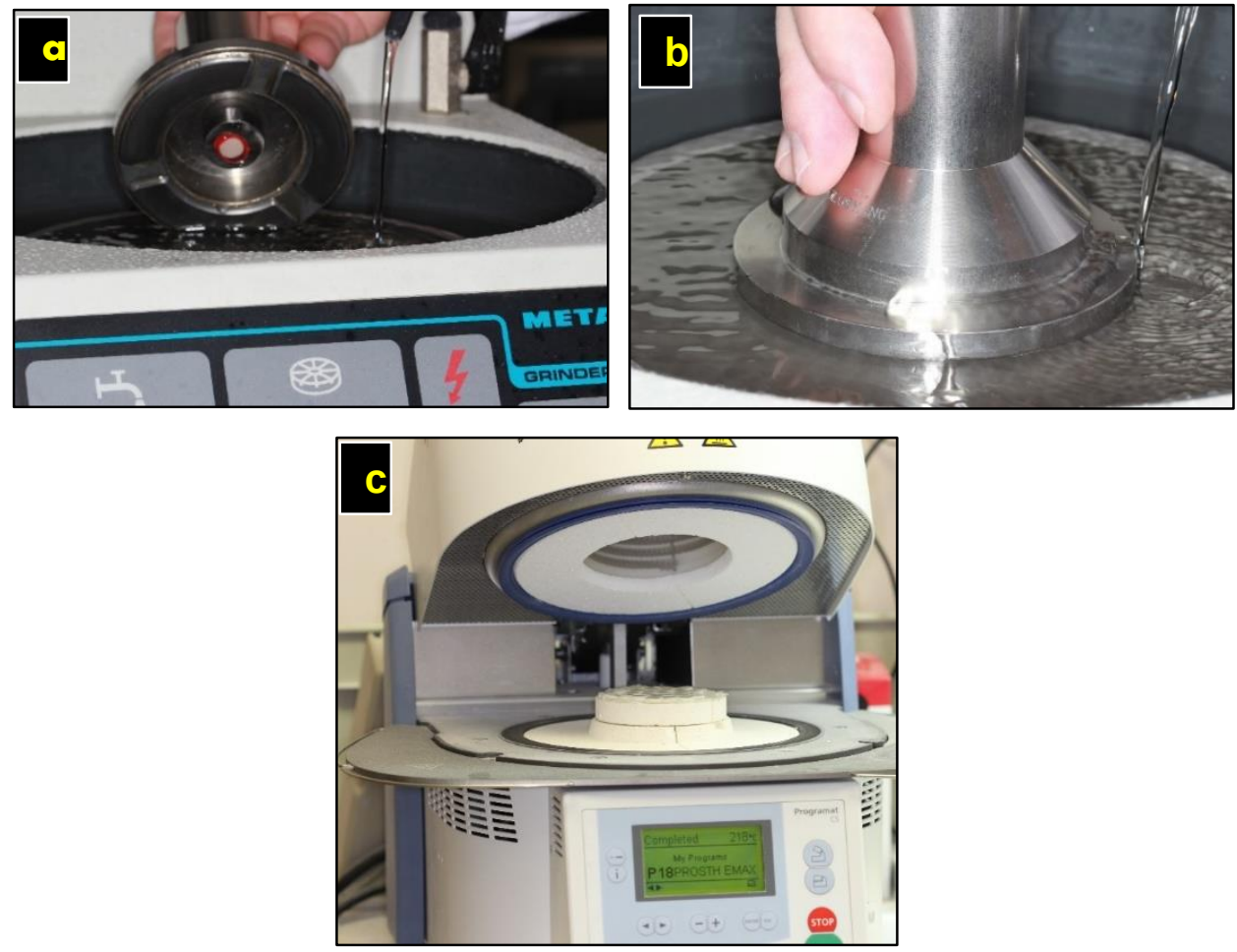

Figure 5.a-c. Preparation of specimens 


\subsection{Treatment of specimens}

\subsubsection{Acid treatment}

For each treatment time, $50 \mathrm{ml}$ of stimulated artificial gastric acid was prepared fresh prior to the exposure of specimens using the following formula recommended by the manufacturer:

$50 \mathrm{ml}$ of $0.2 \%(\mathrm{w} / \mathrm{v})$ Sodium chloride in $0.7 \%(\mathrm{v} / \mathrm{v})$ Hydrochloric acid (Ricca Chemical Company, Arlington, TX; Cat \# 7108-16) mixed with 0.16g of pepsin powder (Fisher Chemical ${ }^{\mathrm{TM}}$; Code S25459, Figure 6.a).

The $\mathrm{pH}$ of the solution was maintained at 2.0.50\% $\mathrm{NaOH}$ was used as a buffer to maintain the $\mathrm{pH}$ at 2.0, using a $\mathrm{pH}$ measuring probe. (Accumet ${ }^{\mathrm{TM}} \mathrm{AB} 15$ Basic pH meter; Fisher Scientific ${ }^{\mathrm{TM}}$, Figure 6.b).

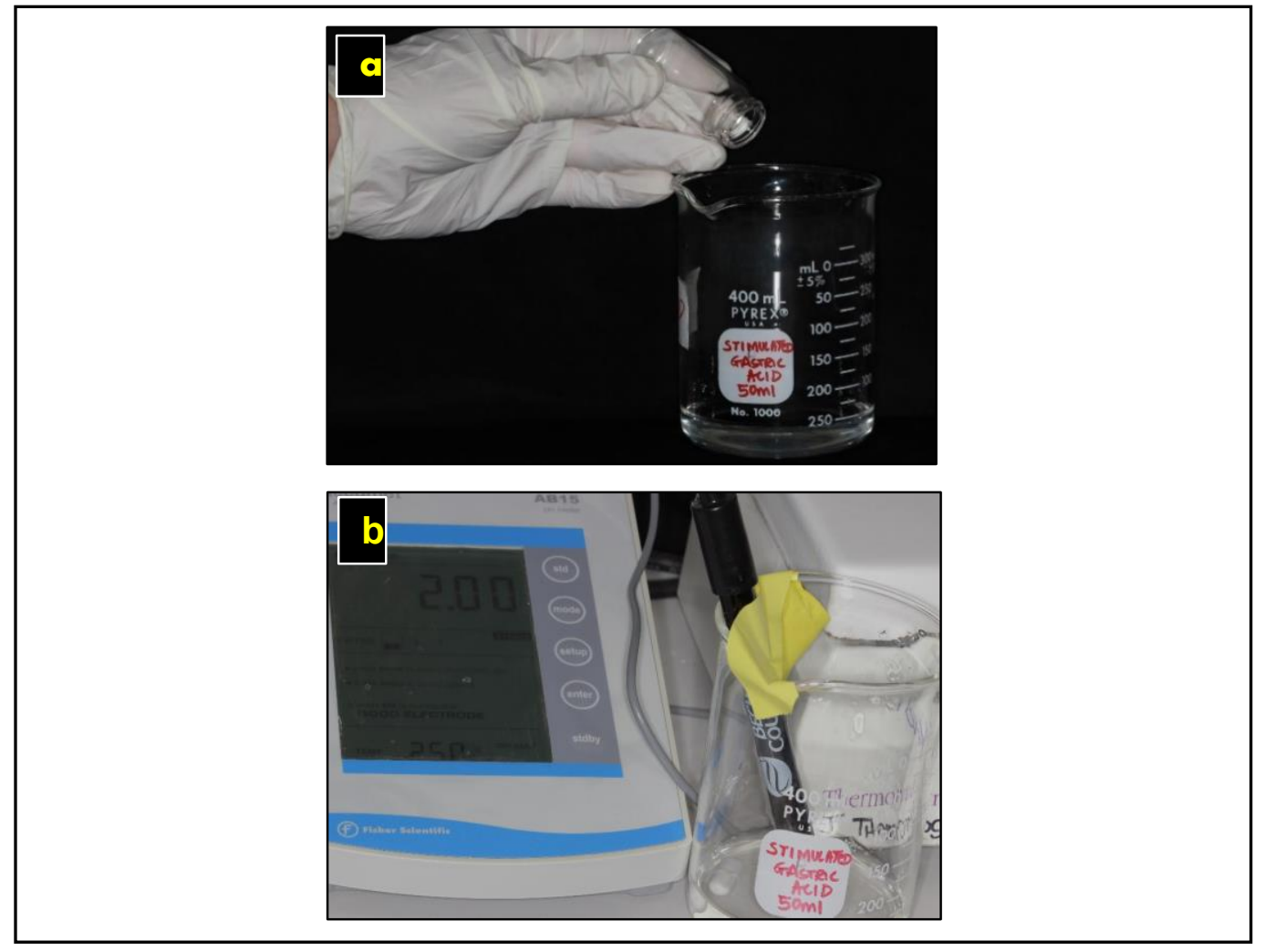

Figure 6.a-b. Preparation of artificial stimulated gastric acid 
Glass beakers were used to immerse the specimens in the acid, the unexposed side was marked for identification. The specimens were immersed in the prepared solution for 2 minutes, followed by rinsing with distilled water for 2 minutes. (Figure 7.a-b). Following the acid treatment, the specimens were stored in distilled water at $37^{\circ} \mathrm{C}$. The procedure was repeated for Groups $B$ and $D$ for 6 times / day for 9 days. The specimens from Group D were then cleaned in preparation for tooth-brush abrasion treatment.
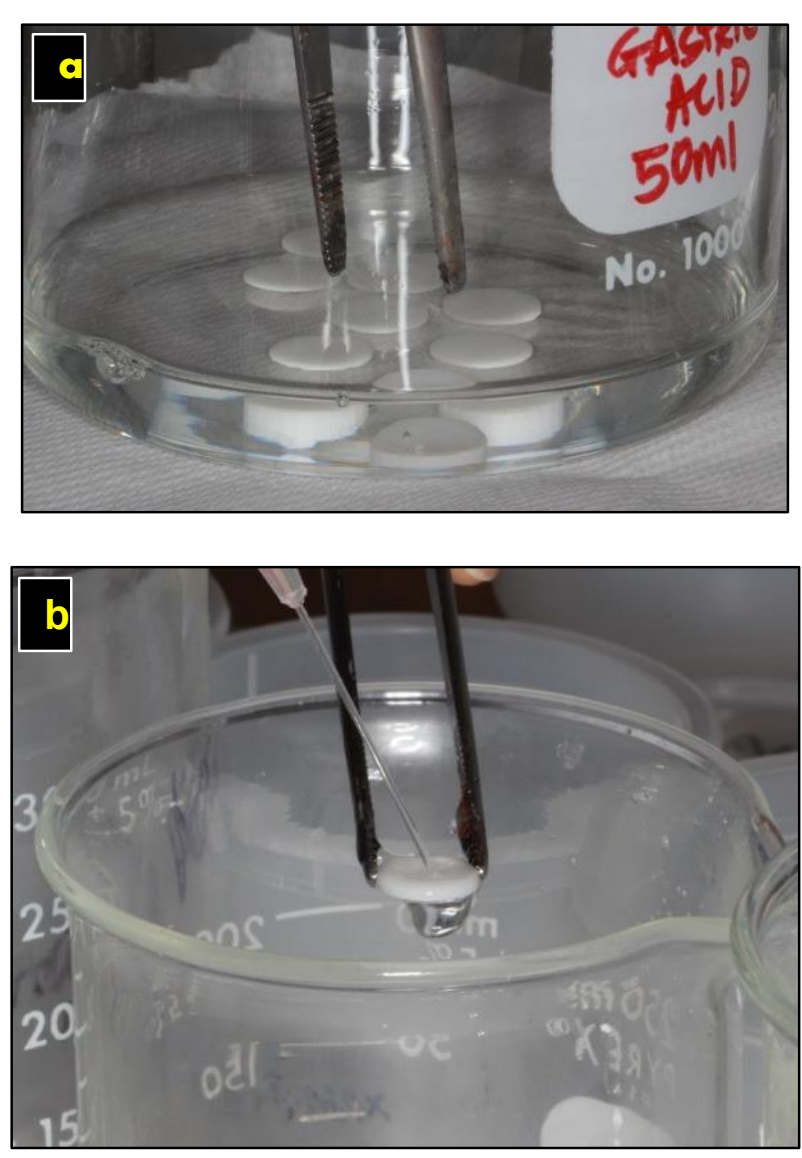

Figure 7.a-b. Acid treatment of the specimens 


\subsubsection{Tooth brush abrasion}

Groups B and D were subjected to tooth brush abrasion using a cross brushing machine as per design specifications of the American Dental Association (V8 Cross Brushing Machine, Sabri Dental Enterprises, Inc.; ISO/DIS standard specification no. 11609, Figure 9.a). Brush heads of standard toothbrushes (Acclean Action Plus, Henry Schein ${ }^{\circledR}$, Figure 8.a) which follow ADA design specifications were mounted on the machine for every time of exposure. A dentifrice slurry was prepared using a non-abrasive standard dentifrice (Colgate ${ }^{\circledR}$ Cavity Protection Toothpaste, Figure 8.b) by diluting the dentifrice in distilled water with a $1: 2$ ratio $(26 \mathrm{~g}$ of dentifrice $: 52 \mathrm{ml}$ of distilled water, Figure 9.c). A fresh slurry was made for each day of the experiment. The specimens were cleaned and mounted on resin blocks (Figure 9.b) the machine set at a frequency of 100 cycles / minute for everyday of brushing for 9 days (Figures 9.d-e). The specimens that received both acid and brushing treatments received the acid exposure ( 6 times/day) first, followed by 100 cycles/minute of brushing.
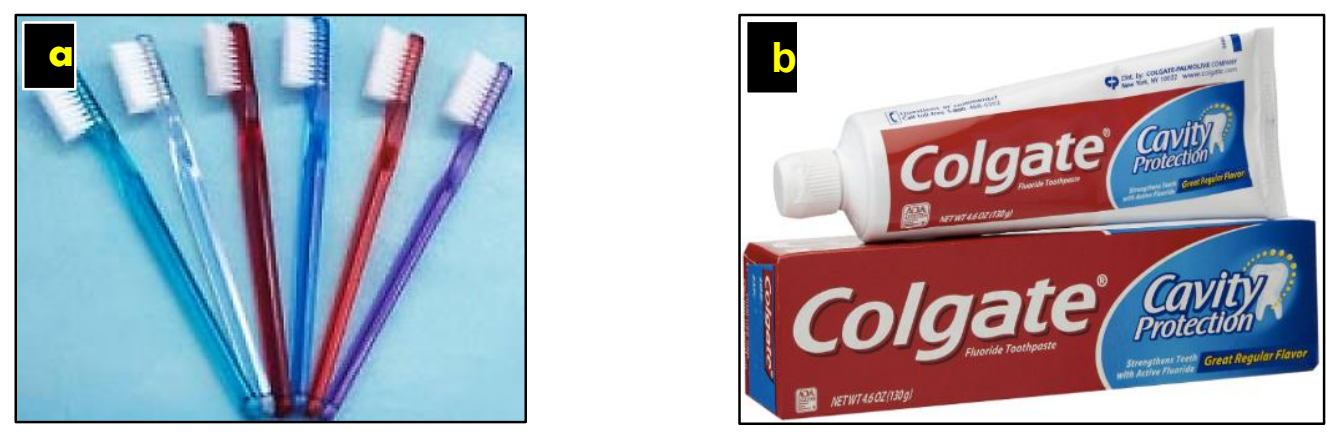

Figure 8.a-b. Tooth brushes and dentifrice as per ADA specifications 


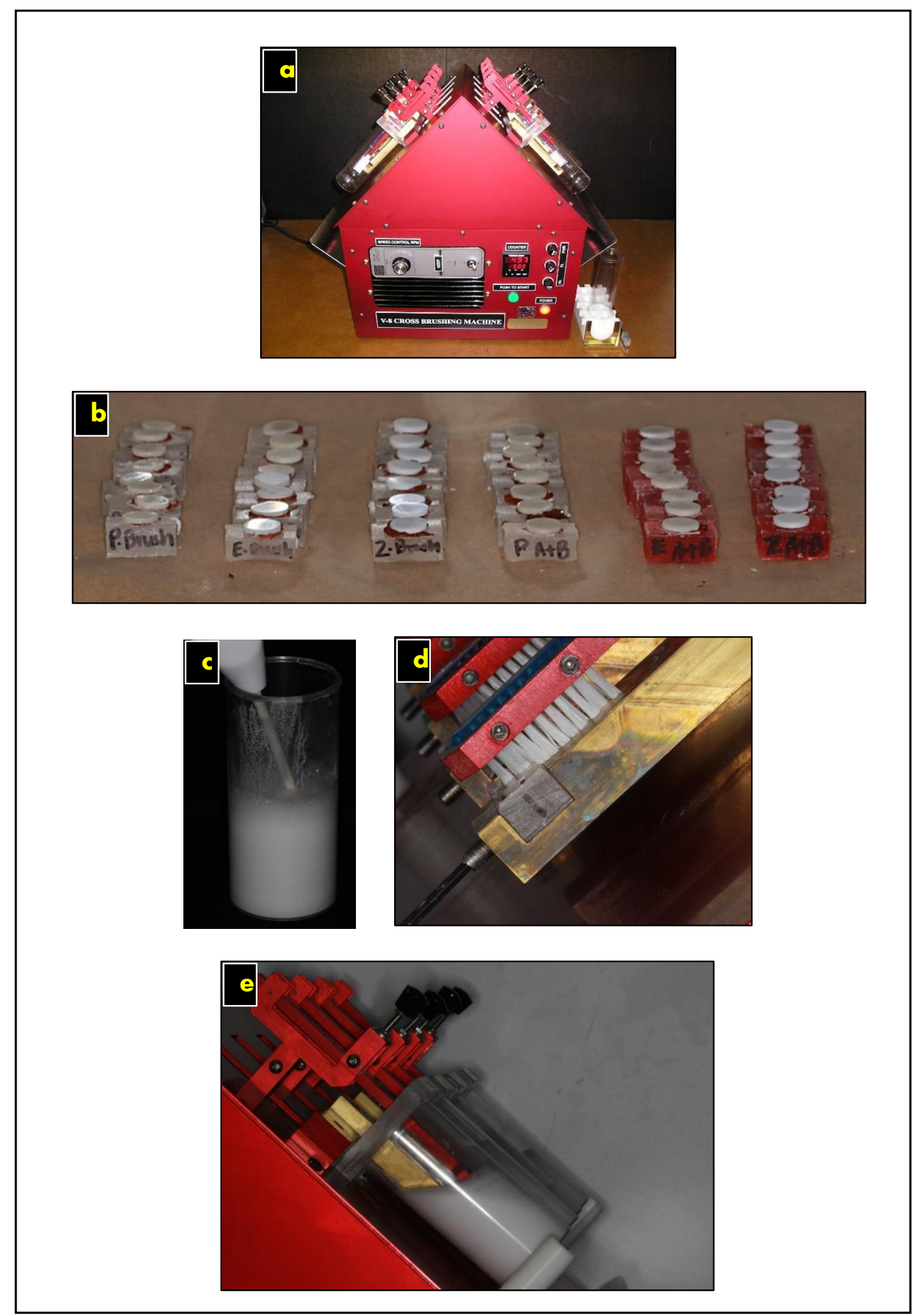

Figure 9 a-e. Tooth brush abrasion of the specimens using the V8 Cross Brushing machine 


\subsection{Morphological assessment of surface topography}

Specimens from each group were randomly selected for morphological assessment using a scanning electron microscope. The selected specimens were thoroughly cleaned, rinsed with distilled water for 5 minutes, dried and fixed onto an aluminum mount and dried. Subsequently, the specimens were lightly sputtered with a gold-palladium alloy (SPI-Module sputter, SPI Supplies, West Chester, PA, USA). The surface topography of the specimens were then using a FEI Quanta 200 Scanning Electron Microscope (FEI, Hillsboro, OR). SEM micrographs of randomly selected specimens of all groups were taken at a 500x, 1000x and $5000 \times$ original magnification.

\subsection{Testing of specimens}

\subsubsection{Optical testing}

\subsubsection{Surface gloss measurement}

A gloss meter (Novo-Curve ${ }^{\mathrm{TM}}$ Glossmeter, Rhopoint ${ }^{\mathrm{TM}}$ Instruments Ltd, Figure 10.a) was used to measure specular reflection gloss of all groups of ceramics. The machine was calibrated as per the manufacturer's recommendations prior to making any measurements. The specimens were cleaned and dried and placed on the instrument for measurement. The surface gloss measurement was noted (in degrees) as the amount of reflected light at an equal but opposite angle to the projecting beam of light from the specimen. (Figure 10.b). 


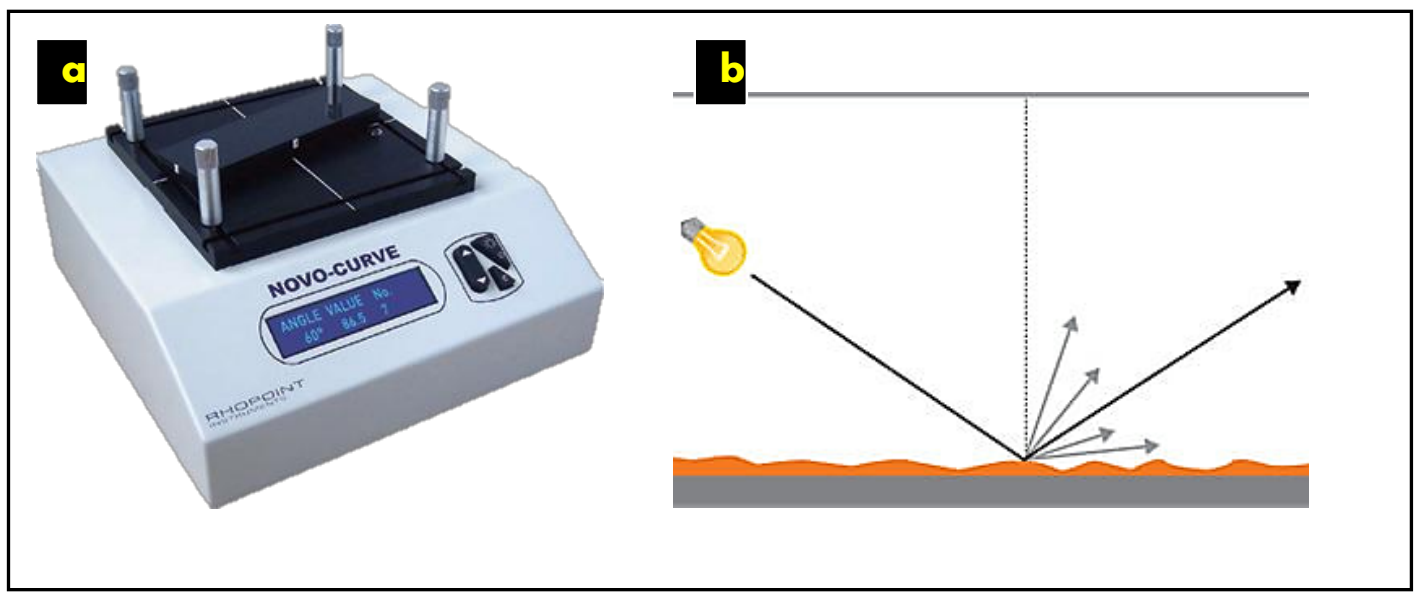

Figure 10.a-b. Surface gloss measurement using glossmeter

\subsubsection{Color and translucency parameter measurement}

A digital spectrophotometer (Gregtag Macbeth ${ }^{\circledR}$ Color-Eye 7000 A, Figure 11) was used to record the CIELAB $\left(L^{*}, a^{*}, b^{*}\right)$ coordinates of all the ceramic samples. The color measurements were made relative to the CIE standard illuminant D65 (as defined by the International Commission on Illumination) which corresponds to average daylight (including ultraviolet wavelength region with a correlated color temperature of $6504 \mathrm{~K}$ ). The Specular Component Excluded (SCE) geometry was determined according to the CIE $L^{*} a^{*} b^{*}$ color scale using standard illuminant D65 over a black background, where (SCE) refers to specular component excluded, $L^{*}$ refers to the lightness, $a^{*}$ to redness to greenness, and $b^{*}$ to yellowness to blueness. Additionally, for the translucency parameter (TP) measurements, a standard white background was used. Calibration of the spectrophotometer was executed as per the manufacturer's recommendations before measurement of the specimens. 


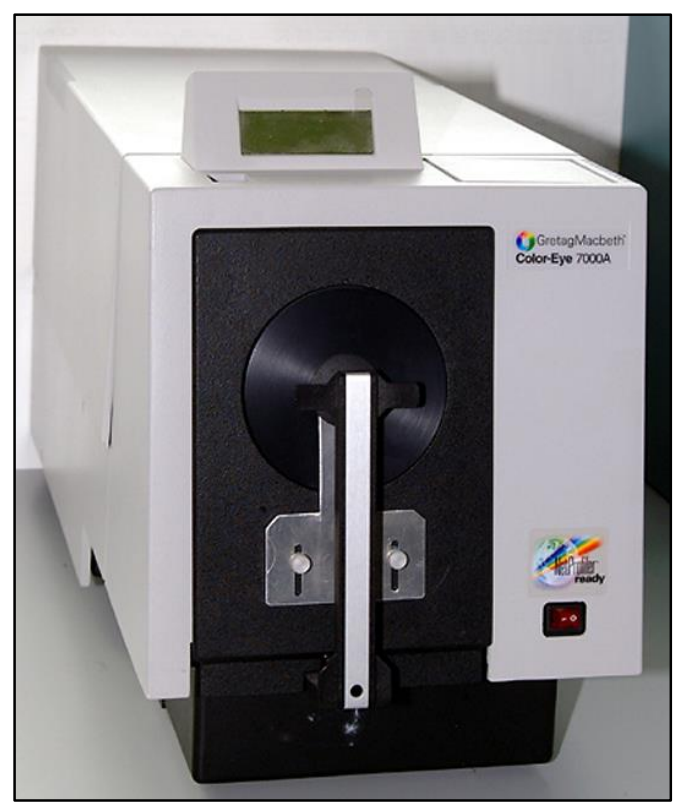

Figure 11. Spectrophotometer

Color calculations were made using the CIE $L^{*} a^{*} b^{*}$ readings in the following formula:

$$
\Delta E=\left(L^{* 2}+a^{\star 2}+b^{\star 2}\right)^{1 / 2}
$$

The TP of each specimen was obtained by calculating the color difference between the specimen against the white background $(w)$ and against the black background $(b)$ using the following equation:

$$
T P=\left\{(L b *-L W *)^{2}+(a b *-a W *)^{2}+(b b *-b W *)^{2}\right\}^{1 / 2}
$$




\subsubsection{Surface roughness measurement}

A stylus (contact) profilometer (Veeco DEKTAK 150 Profilometer, Bruker Corporation, Figure 12) was used to measure surface roughness values of all the ceramic specimens. The specimens were cleaned, dried and stabilized on a mount for measurements. The profilometer was calibrated as per the recommendations of the manufacturer before measurements of each group. Three roughness measurements (Ra in $\mu \mathrm{m}$ ) were made for each specimen. A diamond stylus (NHT6) of $2 \mu \mathrm{m}$ radius and $90^{\circ}$ stylus angle was crossed over at a constant speed across each of the finished ceramic specimens with a force of $0.7 \mathrm{~N}$. All the measurements were made as close as possible to the center of the specimen as possible. Three measurements were made for each specimen and the mean was calculated to record the surface features. The Ra value obtained represented the mean value for a surface that has been traced by the profilometer. ${ }^{64-65} \mathrm{~A}$ lower Ra value is indicative of a smoother surface. ${ }^{66}$

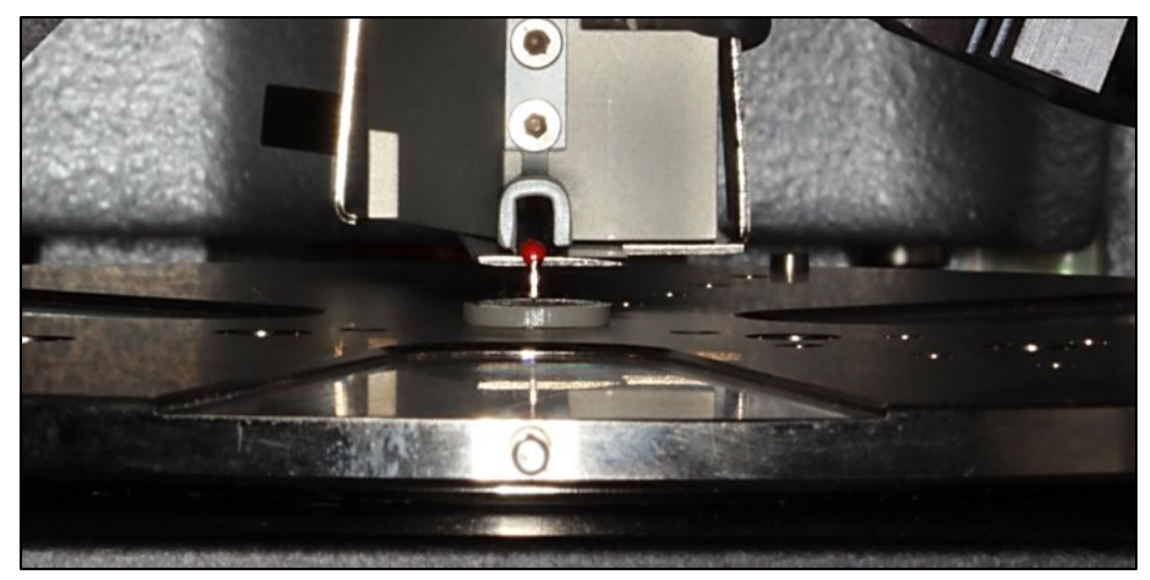

Figure 12. Stylus profilometer 


\subsubsection{Biaxial flexural strength measurement}

Specimens from all the groups were subjected to strength measurements. The specimens were cleaned and dried prior to testing. The piston-on-three-ball test as per ASTM Standard F394-7867 was used to determine the biaxial flexural strength (BFS). The diameter of the mount was $10 \mathrm{~mm}$ to accommodate the $10 \mathrm{~mm}$ diameter ceramic specimens. This dimension was used for the specimens to more closely simulate dental restorations and have a more realistic depiction of strength values.

The thickness of the specimen center was measured with a digital micrometer (Digital Caliper-Deluxe Model, RSR Electronics, Inc) before testing. Three steel spheres (1.6 mm diameter) placed on a circle ( $8 \mathrm{~mm}$ diameter $)$ arranged $120^{\circ}$ apart were used to center and support the disk specimens.

The load was applied to the specimen center by a right circular cylinder of hardened steel having a diameter of $0.72 \mathrm{~mm}$ with the flat end perpendicular to the axis at a crosshead speed of $1 \mathrm{~mm} / \mathrm{min}$ until fracture. The testing was performed at room conditions using a universal testing machine (Instron 8871 , Instron ${ }^{\circledR}$, Figure 13) The maximum tensile stress (MPa), which corresponded to the biaxial flexure strength, was calculated according to the equation suggested by the test standard (ASTM F394-78) as follows:

$$
S=-0.2387 P(X-Y) / d^{2}
$$

S- Maximum tensile stress (MPa)

P- Load at fracture $(\mathrm{N})$

d- Specimen thickness $(\mathrm{mm})$ at fracture origin 
$\mathrm{X}=(1+\mathrm{v}) \ln (\mathrm{B} / \mathrm{C})^{2}+[(1-\mathrm{v}) / 2](\mathrm{B} / \mathrm{C})^{2}$

$\mathrm{Y}=(1+\mathrm{v})\left[1+\ln (\mathrm{A} / \mathrm{C})^{2}\right]+(1-\mathrm{v})(\mathrm{A} / \mathrm{C})^{2}$

v- Poisson's ratio

A- Radius of the support circle $(\mathrm{mm})$

B- Radius of the tip of the piston ( $\mathrm{mm}$ )

C- Radius of the specimen ( $\mathrm{mm})$.

The Poisson's ratio was assumed to be 0.25 for feldspathic porcelain and IPS e.max ceramics and 0.30 for monolithic zirconia.

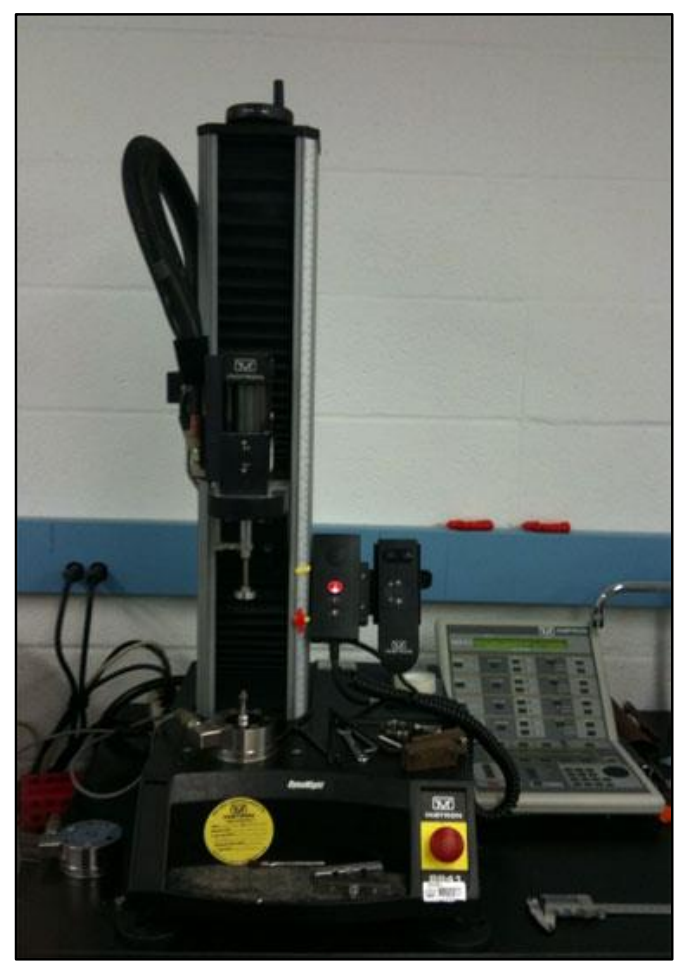

Figure 13. Instron 8871 universal testing machine 


\subsection{Statistical analysis}

Descriptive statistics were used on all the raw data obtained from different testing. A one-way between groups analysis of variance (ANOVA) was conducted to compare the effect of different treatments (Acid only, Brush only, Acid + Brush) on optical characteristics (surface gloss, color and translucency) and mechanical behavior (biaxial flexural strength) on the three types of ceramics. A Tukey HSD post hoc test was used for all post-hoc comparisons. 


\section{CHAPTER 3: RESULTS}

\subsection{Surface gloss results}

A one-way between groups ANOVA was conducted to compare the effect of acid environment and tooth brushing on the surface gloss in three types of ceramics. A TukeyHSD post hoc test was used for all post-hoc comparisons. Descriptive statistics are presented in Table 7. Results obtained are as follows:

- There was no significant effect of acid and brushing treatment on gloss at the $p<0.05$ level for IPS e.max ceramics $[F(3,28)=2.69, p=0.065]$.

- There was a significant effect of acid and brushing treatment on gloss at the $p$ $<0.05$ level for feldspathic porcelain $\left[F(3,28)=4.25, p=0.013, \eta^{2}=0.31\right]$. We see a significant difference between the control group A vs. acid only group B [difference $=18.21,95 \% \mathrm{Cl}(3.45,32.96), p=0.011]$.

- There was no significant effect of acid and brushing treatment on gloss at the $p<0.05$ level for zirconia ceramic $[F(3,28)=1.91, p=0.150]$. 


\begin{tabular}{|c|c|c|c|c|}
\hline GROUP & PARAMETERS & $\begin{array}{l}\text { IPS } \\
\text { e.max }\end{array}$ & PORCELAIN & ZIRCONIA \\
\hline \multirow{5}{*}{$\begin{array}{l}\text { GROUP A- } \\
\text { CONTROL }\end{array}$} & $\mathrm{N}$ & 8 & 8 & 8 \\
\hline & Mean & 22.81 & 69.54 & 100.13 \\
\hline & SD & 13.50 & 11.63 & 12.65 \\
\hline & Min & 11.30 & 46.90 & 78.80 \\
\hline & Max & 53.50 & 79.50 & 120.80 \\
\hline \multirow[t]{5}{*}{$\begin{array}{l}\text { GROUP B- } \\
\text { ACID ONLY }\end{array}$} & $\mathrm{N}$ & 8 & 8 & 8 \\
\hline & Mean & 15.08 & 51.33 & 78.31 \\
\hline & SD & 6.23 & 9.36 & 31.34 \\
\hline & Min & 7.50 & 35.80 & 7.10 \\
\hline & Max & 24.00 & 62.00 & 98.90 \\
\hline \multirow[t]{5}{*}{$\begin{array}{l}\text { GROUP C- } \\
\text { BRUSH }\end{array}$} & $\mathrm{N}$ & 8 & 8 & 8 \\
\hline & Mean & 16.05 & 55.30 & 95.39 \\
\hline & SD & 5.45 & 13.99 & 7.74 \\
\hline & Min & 6.10 & 37.40 & 83.50 \\
\hline & Max & 22.50 & 79.50 & 105.30 \\
\hline \multirow[t]{5}{*}{$\begin{array}{l}\text { GROUP D- } \\
\text { ACID+BRUSH }\end{array}$} & $\mathrm{N}$ & 8 & 8 & 8 \\
\hline & Mean & 10.99 & 60.60 & 95.68 \\
\hline & SD & 5.93 & 6.98 & 18.61 \\
\hline & Min & 3.60 & 50.30 & 60.90 \\
\hline & Max & 22.90 & 70.70 & 116.30 \\
\hline
\end{tabular}

Table 7. Descriptive Statistics for Surface gloss

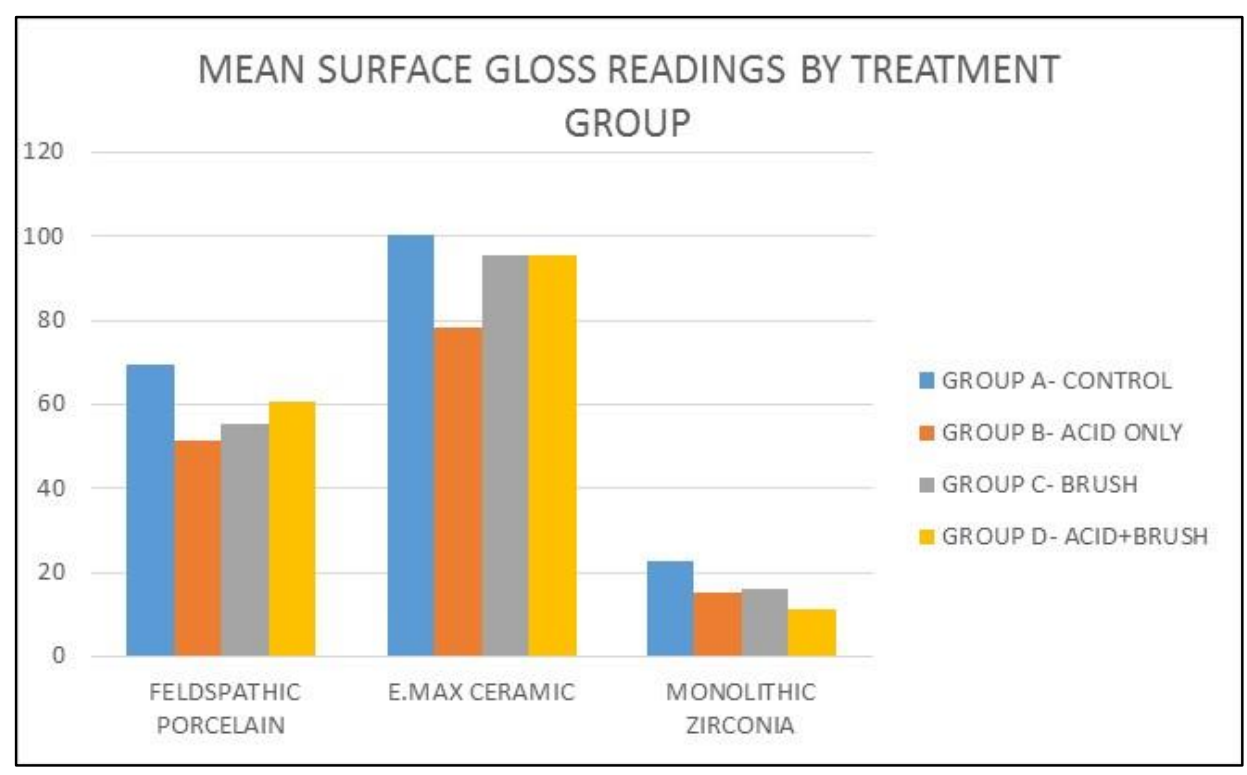

Figure 14. Mean surface gloss readings by treatment group 


\subsection{Color results}

A one-way between groups ANOVA was conducted to compare the effect of acid environment on color in three types of ceramics. A TukeyHSD post hoc test was used for all post-hoc comparisons. Descriptive statistics are presented in Table 8. Results are as follows:

- There was a significant effect of acid and brushing treatment on color at the $p$ $<0.05$ level for IPS e.max $\left[F(3,28)=3.09, p=0.043, \eta^{2}=0.25\right]$. We see a significant difference between the control group A vs. brush only group C [difference $=3.43,95 \% \mathrm{Cl}(0.19,5.67), p=0.035$ ].

- There was no significant effect of acid and brushing treatment on color at the $p$ $<0.05$ level for Porcelain $[F(3,28)=1.77, p=0.176]$.

- There was no significant effect of acid and brushing treatment on color at the $p$ $<0.05$ level for Zirconia $[\mathrm{F}(3,28)=1.94, p=0.255]$. 


\begin{tabular}{|c|c|c|c|c|}
\hline $\begin{array}{c}\text { GROUP } \\
\begin{array}{c}\text { GROUP A- } \\
\text { CONTROL }\end{array}\end{array}$ & PARAMETER & IPS e.max & PORCELAIN & ZIRCONIA \\
\hline & Mean & 56.82 & 58.13 & 8 \\
\hline & SD & 1.43 & 3.04 & 72.21 \\
\hline & Min & 55.13 & 50.93 & 69.40 \\
\hline $\begin{array}{c}\text { GROUP B- ACID } \\
\text { ONLY }\end{array}$ & $\mathrm{N}$ & 59.58 & 60.66 & 74.68 \\
\hline & Mean & 57.76 & 58.79 & 73.40 \\
\hline & $\mathrm{SD}$ & 1.08 & 0.97 & 0.70 \\
\hline & Min & 56.45 & 57.38 & 72.70 \\
\hline & $\mathrm{Max}$ & 59.47 & 60.65 & 74.66 \\
\hline $\begin{array}{c}\text { GROUP C- } \\
\text { BRUSH }\end{array}$ & $\mathrm{N}$ & 8 & 8 & 8 \\
\hline & $\mathrm{SD}$ & 60.36 & 59.15 & 72.81 \\
\hline & $\mathrm{Min}$ & 56.83 & 58.04 & 71.28 \\
\hline & $\mathrm{Max}$ & 69.76 & 61.59 & 74.23 \\
\hline & $\mathrm{N}$ & 8 & 8 & 8 \\
\hline $\begin{array}{c}\text { GROUP D- } \\
\text { ACID+BRUSH }\end{array}$ & Mean & 57.97 & 60.05 & 72.99 \\
\hline & $\mathrm{SD}$ & 1.35 & 0.46 & 0.82 \\
\hline & $\mathrm{Min}$ & 56.12 & 59.27 & 71.68 \\
\hline & $\mathrm{Max}$ & 59.97 & 60.56 & 74.21 \\
\hline
\end{tabular}

Table 8. Descriptive Statistics for Color

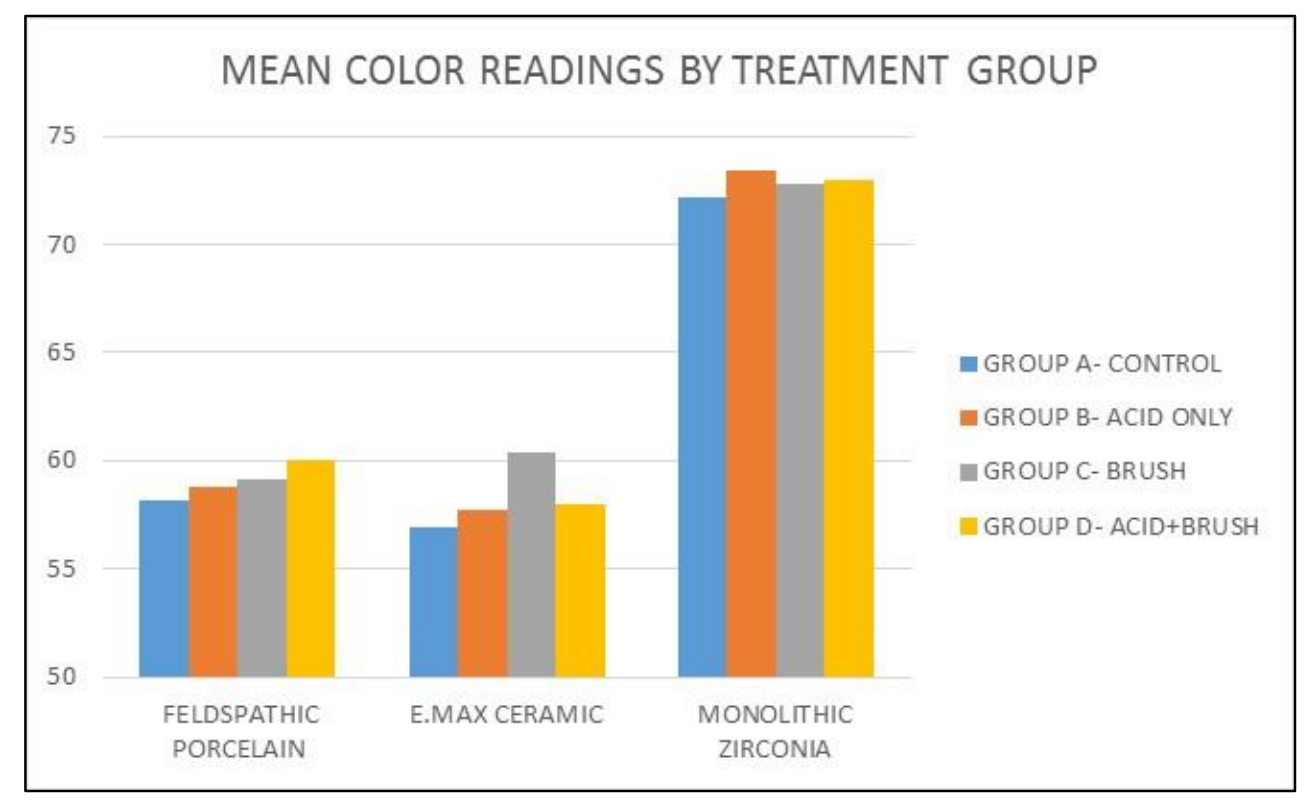

Figure 15. Mean color readings by treatment group 


\subsection{Translucency parameter results}

A one-way between groups ANOVA was conducted to compare the effect of acid and brushing treatment on the translucency parameter on three types of ceramics. A TukeyHSD post hoc test was used for all post-hoc comparisons. Descriptive statistics are presented in Table 9. Results are as follows:

- There was no significant effect of acid and brushing treatment on translucency at the $p<0.05$ level for IPS e.max $[F(3,28)=0.48, p=0.700]$.

- There was no significant effect of acid and brushing treatment on translucency at the $p<0.05$ level for Porcelain $[F(3,28)=0.18, p=0.9119]$.

- There was no significant effect of acid and brushing treatment on translucency at the $p<0.05$ level for Zirconia $[\mathrm{F}(3,28)=0.50, \mathrm{p}=0.685]$. 


\begin{tabular}{|c|c|c|c|c|}
\hline GROUP & PARAMETER & $\begin{array}{c}\text { IPS } \\
\text { e.max }\end{array}$ & PORCELAIN & ZIRCONIA \\
\hline GROUP A- CONTROL & $\mathrm{N}$ & 8 & 8 & 8 \\
\hline & Max & 10.22 & 12.03 & 4.44 \\
\hline & Mean & 8.49 & 7.37 & 3.92 \\
\hline GROUP B- ACID ONLY & SD & 1.01 & 0.58 & 0.58 \\
\hline & Min & 6.34 & 6.76 & 2.76 \\
\hline & Mean & 8.49 & 7.37 & 3.92 \\
\hline & SD & 1.01 & 0.58 & 0.58 \\
\hline GROUP C- BRUSH ONLY & Min & 6.34 & 6.76 & 2.76 \\
\hline & Max & 9.69 & 8.52 & 4.63 \\
\hline & Mean & 8.13 & 7.59 & 3.29 \\
\hline & SD & 1.10 & 0.97 & 1.33 \\
\hline GROUP D- ACID+BRUSH & Min & 6.69 & 5.82 & 0.77 \\
\hline & Max & 9.72 & 8.91 & 4.61 \\
\hline & SD & 7.91 & 7.42 & 3.49 \\
\hline & Min & 6.05 & 6.94 & 1.36 \\
\hline & Max & 9.12 & 8.70 & 4.35 \\
\hline
\end{tabular}

Table 9. Descriptive statistics for translucency parameter

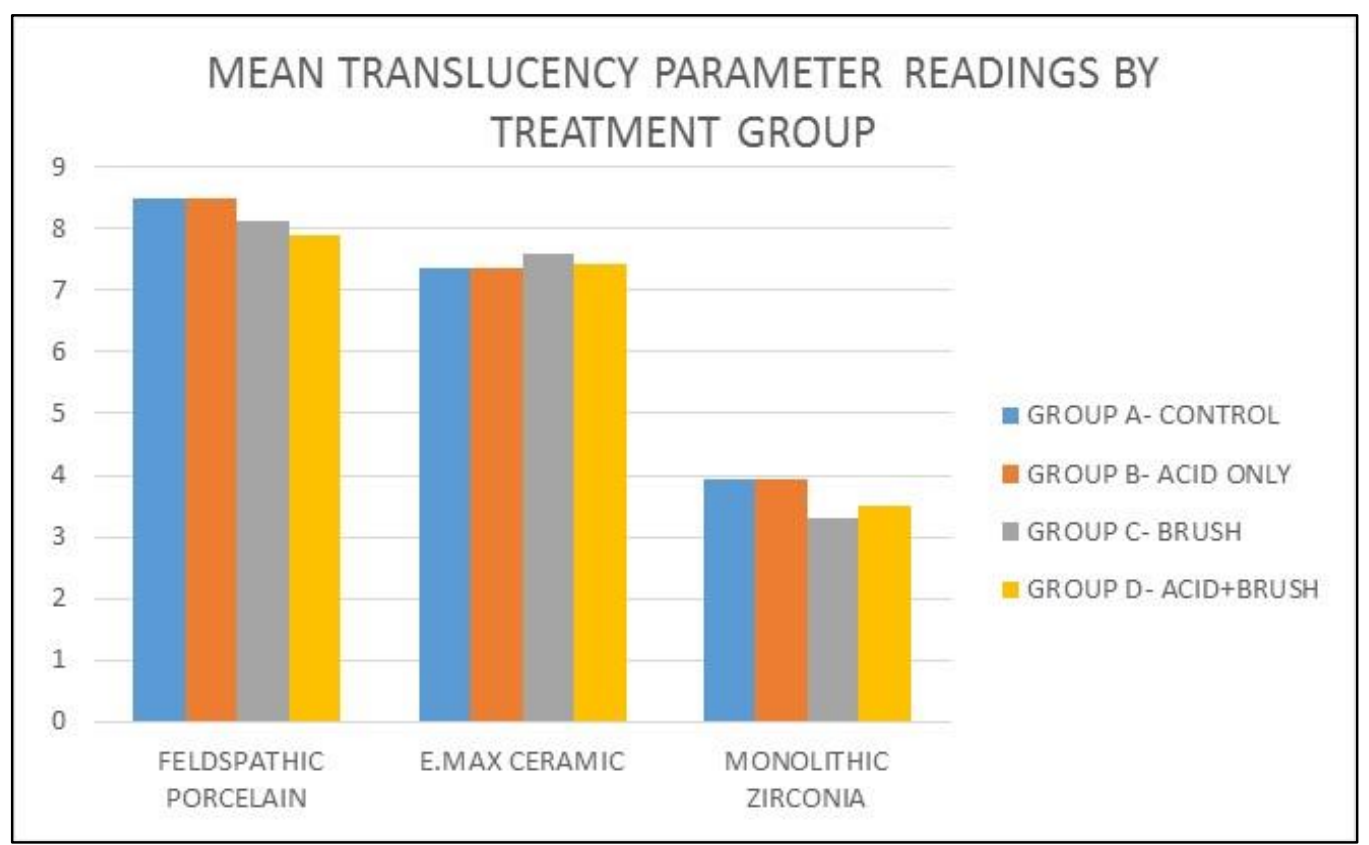

Figure 16. Mean translucency parameter readings by treatment group 


\subsection{Surface roughness results}

A one-way between groups ANOVA was conducted to compare the effect of acid and brushing treatment on surface roughness in three types of ceramics. A TukeyHSD post hoc test was used for all post-hoc comparisons. Descriptive statistics are presented in Table 10. Results are as follows:

- There was a significant effect of acid and brushing treatment on surface roughness at the $p<0.05$ level for IPS e.max $\left[F(3,92)=3.44, p=0.020, \eta^{2}=\right.$ 0.11]. We see a significant difference between the control group A vs. acid + brush group $\mathrm{D}$ [difference $=0.17,95 \% \mathrm{Cl}(0.01,0.33)$ ]

- There was a significant effect of acid and brushing treatment on surface roughness at the $p<0.05$ level for Porcelain $\left[F(3,28)=15.52, p<0.000, \eta^{2}=\right.$ 0.27].]. We see the following significant differences:

○ Brush vs. Acid [difference $=0.59,95 \% \mathrm{Cl}(0.12,1.05), p=0.007$ ]

○ Control vs. Acid [difference $=1.18,95 \% \mathrm{Cl}(0.71,1.64), p<0.000$ ]

○ Brush vs. Acid+Brush [difference $=0.80,95 \% \mathrm{Cl}(0.34,1.26), p<0.000$ ].

○ Control vs. Brush [difference $=0.59,95 \% \mathrm{Cl}(0.13,1.05), p<0.006$ ].

- There was no significant effect of acid and brushing treatment on surface roughness at the $p<0.05$ level for Zirconia $[F(3,28)=11.19, p<0.000]$.

○ Control vs. Acid [difference $=0.19,95 \% \mathrm{Cl}(0.05,0.33), p=0.002$ ]

○ Control vs. Acid+Brush [difference $=0.28,95 \% \mathrm{Cl}(0.14,0.41), p<0.000$ ].

○ Control vs. Brush [difference $=0.23,95 \% \mathrm{Cl}(0.09,0.37), p<0.000]$. 


\begin{tabular}{|c|c|c|c|c|}
\hline $\begin{array}{c}\text { GROUP } \\
\text { GROUP A- } \\
\text { CONTROL }\end{array}$ & PARAMETER & IPS e.max & PORCELAIN & ZIRCONIA \\
\hline & Mean & 24 & 24 & 24 \\
\hline & SD & 0.36 & 0.47 & 0.19 \\
\hline & Min & 0.22 & 0.25 & 0.16 \\
\hline $\begin{array}{c}\text { GROUP B- ACID } \\
\text { ONLY }\end{array}$ & Max & 0.51 & 1.13 & 0.07 \\
\hline & Mean & 24 & 24 & 24 \\
\hline & SD & 0.43 & 1.66 & 0.39 \\
\hline & Min & 0.23 & 0.83 & 0.13 \\
\hline & Max & 1.11 & 4.21 & 0.21 \\
\hline GROUP C- BRUSH & $\mathrm{N}$ & 24 & 24 & 0.70 \\
\hline & Mean & 0.52 & 1.06 & 0.43 \\
\hline & SD & 0.26 & 0.60 & 0.21 \\
\hline & Min & 0.24 & 0.31 & 0.20 \\
\hline & Max & 1.24 & 2.49 & 1.20 \\
\hline GROUP D- & $\mathrm{N}$ & 24 & 24 & 24 \\
\hline ACID+BRUSH & Mean & 0.53 & 1.27 & 0.47 \\
\hline & SD & 0.29 & 0.63 & 0.21 \\
\hline & Min & 0.21 & 0.43 & 0.22 \\
\hline & Max & 1.39 & 2.40 & 1.01 \\
\hline
\end{tabular}

Table 10. Descriptive statistics for surface roughness

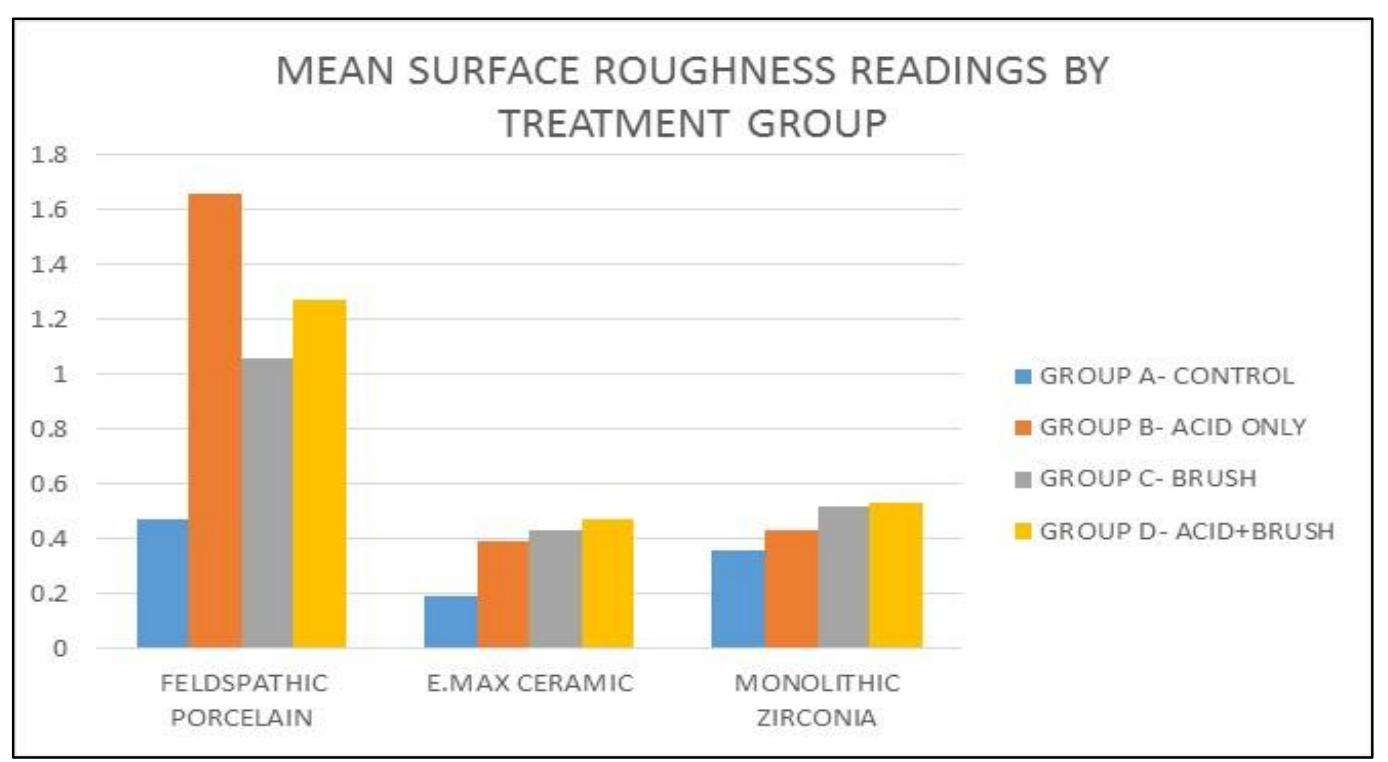

Figure 17. Mean surface roughness readings by treatment group 


\subsection{Biaxial Flexural Strength results}

A one-way between groups ANOVA was conducted to compare the effect of acid and brushing treatment on the biaxial flexural strength in three types of ceramics. A TukeyHSD post hoc test was used for all post-hoc comparisons. Descriptive statistics are presented in Table 11. Results are as follows:

- There was no significant effect of acid and brushing treatment on flexural strength at the $p<0.05$ level for IPS e.max $[F(3,28)=1.59, p=0.214]$.

- There was no significant effect of acid and brushing treatment on flexural strength at the $p<0.05$ level for Porcelain $[F(3,28)=0.05, p=0.983]$.

- There was no significant effect of acid and brushing treatment on flexural strength at the $p<0.05$ level for Zirconia $[\mathrm{F}(3,28)=1.05, p=0.386]$. 


\begin{tabular}{|c|c|c|c|c|}
\hline GROUP & PARAMETER & IPS e.max & PORCELAIN & ZIRCONIA \\
\hline $\begin{array}{c}\text { GROUP A- } \\
\text { CONTROL }\end{array}$ & $\mathrm{N}$ & 8 & 8 & 8 \\
\hline & Mean & 297.16 & 120.93 & 1093.35 \\
\hline & $\mathrm{SD}$ & 51.81 & 56.93 & 139.91 \\
\hline & Min & 209.38 & 0.00 & 886.33 \\
\hline GROUP B- ACID & Max & 369.60 & 177.04 & 1337.47 \\
\hline & $\mathrm{N}$ & 8 & 8 & 8 \\
\hline & Mean & 342.75 & 125.10 & 1057.57 \\
\hline & Min & 64.38 & 32.55 & 165.52 \\
\hline & Max & 265.49 & 80.97 & 790.07 \\
\hline GROUP C- BRUSH & $\mathrm{N}$ & 8 & 8 & 1323.90 \\
\hline & Mean & 293.76 & 120.61 & 1086.24 \\
\hline & $\mathrm{SD}$ & 81.63 & 26.39 & 96.48 \\
\hline & Min & 142.92 & 87.39 & 938.72 \\
\hline & Max & 429.70 & 165.64 & 1207.38 \\
\hline & $\mathrm{N}$ & 8 & 8 & 8 \\
\hline GROUP D- & Mean & 342.54 & 117.44 & 971.97 \\
\hline ACID+BRUSH & $\mathrm{SD}$ & 38.89 & 31.75 & 195.99 \\
\hline & Min & 278.96 & 53.60 & 713.32 \\
\hline & Max & 391.38 & 146.12 & 1369.80 \\
\hline & & & &
\end{tabular}

Table 11. Descriptive statistics for flexural strength

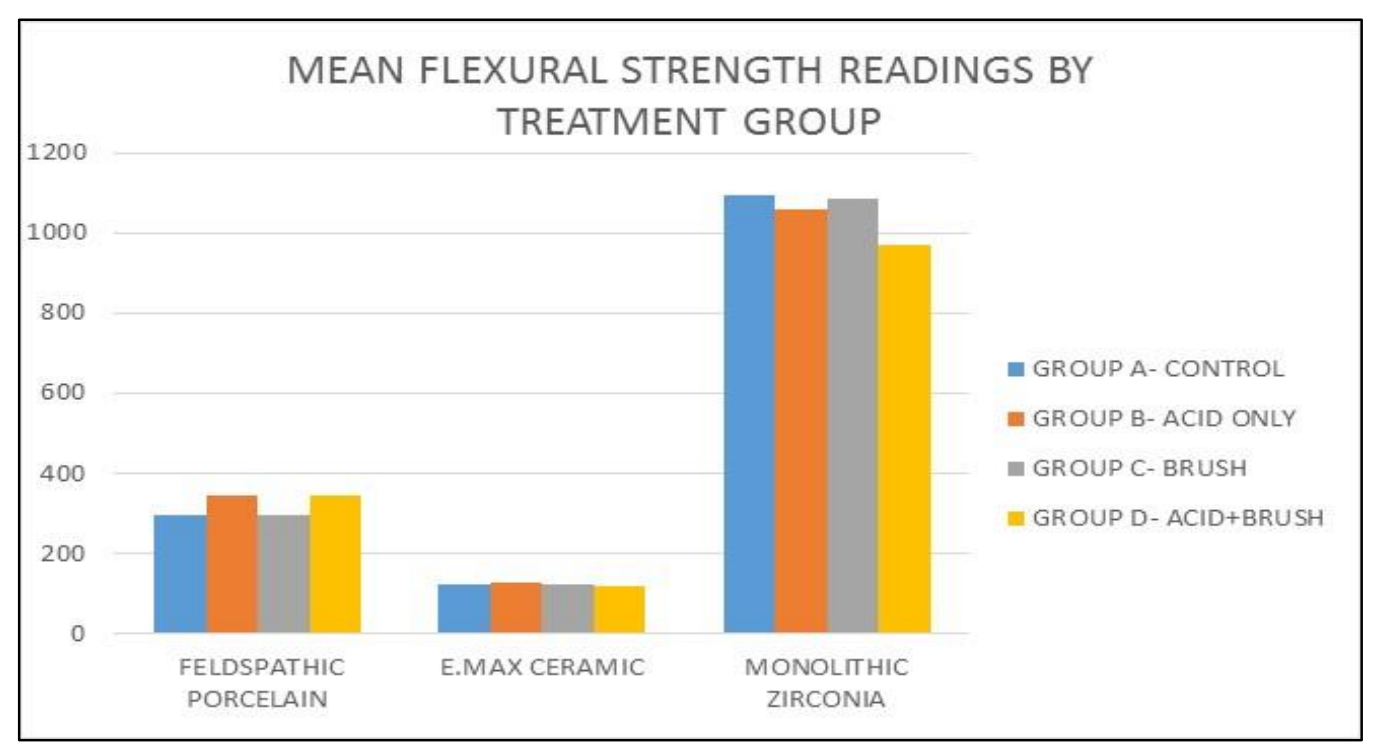

Figure 18. Mean flexural strength readings by treatment group 


\section{CHAPTER 4: DISCUSSION}

This study was conducted to compare the effects of gastric acid induced surface changes, with and without tooth brush abrasion on the optical characteristics and mechanical properties of currently used dental ceramics. Three types of dental ceramics were selected for this study, as representative of currently used dental ceramics in a clinical setting, (Table 5). The ceramics were prepared as $10 \times 1 \mathrm{~mm}$ discs, the size is assumed to more closely mimic dimensions of dental ceramic restorations. Each specimen received the same timed treatment of polishing and heat treatment (as recommended by the manufacturer) to ensure uniformity. The materials were divided into four groups based on the treatments that they received, summarized in Table 6. The protocol was adopted from previous studies and modified to test the proposed hypothesis. Regimens for gastric acid treatment and tooth brush abrasion (summarized in Table 5) were developed and applied to the respective groups. All specimens were stored in distilled water at $37^{\circ} \mathrm{C}$ in an incubator (Thermo Scientific Heratherm General Incubator). Specimens from Group A (Control) received no treatments. Following the 9 day regime of gastric acid treatment and/or toothbrush abrasion, the specimens were subjected to optical and mechanical testing using standardized testing protocols. Following testing, statistical analysis was performed to analyze the results and to determine whether the proposed hypothesis was supported or rejected, discussed in the forthcoming sections. 


\subsection{Study aftermath}

\subsubsection{Changes in functional strength}

The results of the study have rejected the first null hypothesis proposed, i.e. exposure to gastric acid and toothbrush abrasion will negatively impact the functional strength (biaxial flexural strength) of feldspathic porcelain, lithium disilicate and monolithic zirconia ceramics. It was observed in the present study, that the biaxial flexural strength comparisons between groups for all three ceramics used were not statistically significant, (figure 18) indicating that the functional strength of ceramics was not negatively impacted by the changes induced by the acid treatment.

The International Standard Organization (ISO)68 recommends biaxial flexural strength testing as a reliable method to study the functional strength of brittle materials ${ }^{69}$ as the maximum tensile stress occurs within the central loading zone and edge failures are removed. ${ }^{70}$ The optimum strength of ceramic materials depends on the fabrication procedures and presence and location of flaws. ${ }^{71}$ The biaxial flexural strength test used in this study is dependent on the surface finish of the specimens ${ }^{72}$ and for this purpose, the surface finish, thickness and diameter of the specimens was controlled and uniform in the current study.

Functional strength is a significantly desirable property of dental ceramics, especially because increasing numbers of ceramic restorations are being used in the posterior region, where occlusal forces range from 150 to $665 \mathrm{~N} \cdot{ }^{73-74}$ Dental ceramics are brittle materials with high elastic moduli and are more sensitive to 
tensile stresses as compared to compressive stresses produced during mastication. ${ }^{75}$ The paradigm shift towards metal-free restorations in clinical dentistry has given birth to a host of ceramic materials with excellent esthetic and mechanical properties. Although a good deal of research in recent years has focused on enhancing the mechanical properties of ceramics to meet clinical objectives, there are no studies, to the current knowledge of the authors that have examined the effect of a corrosive environment on the functional strength of these materials. It has been seen that on immersion of ceramics in acidic agents for 168 hours, there was in increase in the surface roughness of the ceramics. ${ }^{54}$ There are many implications of increased surface roughness on the mechanical behavior of ceramics $^{57}$ and corrosion can affect the fracture strength of these materials. ${ }^{57-58}$ Surface roughness may potentially impact the strength of ceramics by possibly altering surface flaws. ${ }^{58}$ It has been demonstrated that certain surface treatments which increase the surface irregularities of ceramics ${ }^{76}$ might pose a risk of future failure and negatively impact the fracture resistance of the ceramic restorations. ${ }^{77}$

In the current study, although surface alterations were observed upon acid treatment on the feldspathic porcelain and IPS e.max ceramic specimens, the strength values between the four groups were not statistically significant. Some reduction in strength was noted after acid and brushing treatment for zirconia specimens, however the values were not meaningful. These findings may be attributed to a relatively small sample size per group. Although this finding is favorable, results could differ under dynamic loading conditions. This is because 
dynamic loading lowers the strength of the material, and presence of water and temperature changes can have an effect on strength values. ${ }^{78}$

\subsubsection{Changes in optical characteristics}

The results of the current study have supported the second null hypothesis that gastric acid induced surface change will negatively impact the color of IPS e.max ceramics and surface gloss of feldspathic porcelain. Additionally, results of the current study have rejected the second null hypothesis that gastric acid induced surface change will negatively impact the optical characteristics (color, translucency parameter and surface gloss) of monolithic zirconia ceramics.

The demand for esthetics is only rising, as patients desire "natural" looking restorations. Restorative dentistry, the world over, is on the lookout for the most esthetic ceramic material to satisfy increasing patient demands. One of the most challenging tasks for a restorative dentist is to esthetically match natural teeth and surrounding tissues, due to so many variations in color and shape of natural teeth. ${ }^{79}$ As described by Albert Munsell in 1921, the color of an object is a three dimensional phenomenon, described as hue, value (brightness), and chroma (saturation). ${ }^{79}$ In addition to these dimensions, the perceived shade of an object is also influenced by phenomenon including fluorescence, opalescence, texture, shape and refractive index. Certain opacifiers and oxides have been incorporated by manufacturers in currently used ceramics to aid in adding depth for matching desirable shades. In general, ceramics with increased proportion of glassy matrix 
like feldspathic porcelain and IPS e.max ceramics have superior esthetic properties compared to more opaque ceramics like zirconia. In keeping with technological advances and clinical goals, compositions of currently used ceramics are evolving every day and while most ceramic materials today perform satisfactorily, their longevity in an acidic environment is a matter of concern and remains to be studied. When restoring worn dentitions with ceramic materials in patients with gastric reflux or eating disorders that cause accumulation of highly acidic fluids ( $\mathrm{pH}=1-2)$ in the oral cavity, the clinicians should be mindful of the effect of these acids on the various components of esthetics.

Several in-vitro investigations have demonstrated that exposure of ceramics to corrosive acids affect the surface roughness of ceramic restorations. Figure 17 shows the differences in the surface roughness values ( $R a$ in $\mu \mathrm{m}$ ) as measured by a stylus profilometer after various treatments on the three ceramics in the current study. All three ceramics displayed an increase in surface roughness values. The felspathic porcelain group demonstrated the most significant difference between groups, as follows:

- Brush vs. Acid [difference $=0.59,95 \% \mathrm{Cl}(0.12,1.05), p=0.007$ ]

- Control vs. Acid [difference $=1.18,95 \% \mathrm{Cl}(0.71,1.64), p<0.000$ ]

- Brush vs. Acid+Brush [difference $=0.80,95 \% \mathrm{Cl}(0.34,1.26), p<0.000$ ].

- Control vs. Brush [difference $=0.59,95 \% \mathrm{Cl}(0.13,1.05), p<0.006]$. 
The IPS e.max samples demonstrated a significant difference in surface roughness as well, especially between control group A vs. acid + brush group D [difference $=0.17,95 \% \mathrm{Cl}(0.01,0.33)]$.

This increase in surface roughness of ceramics has the potential to affect light reflection and color perception co-ordinates due to changes in surface topography. A recent in-vitro study by Sulaiman et al demonstrated that translucency parameter significantly increased $(p<0.05)$ for partially stabilized zirconia, translucent zirconia and IPS e.max ceramics, and the surface gloss significantly increased $(p<0.05)$ for IPS e.max, partially stabilized, and fully stabilized zirconia when immersed in artificial gastric acid for $96 \mathrm{~h}$ at $37^{\circ} \mathrm{C}$. For our study, a standard color specification system delevoped by the Commission Internationale de l'Eclairage (CIE, International Commission on Illumination) was used. In this system $\mathrm{X}, \mathrm{Y}$ and $\mathrm{Z}$ stimulus values are obtained from the combination of the object's spectral power distribution and the spectral power distribution of the selected illuminant.

These values can be transformed to $L^{*}, a^{*}$ and $b^{*}$ values where $L^{*}$ is a measure of lightness similar to Value (V) in the Munsell system and the $a^{*}$ and $b^{*}$ values represent positions on a red/green and yellow/blue axis, respectively. ${ }^{80}$ The changes in optical characteristics in the present study are further elaborated. 


\subsubsection{Translucency parameter}

Translucency is the relative amount of light transmitted through the material. ${ }^{81}$ The two common parameters used to measure translucency of dental materials are contrast ratio $(\mathrm{CR})$ and translucency parameter (TP). TP is the color difference between a material of uniform thickness over black and a white background directly corresponding to a common visual assessment of translucency. ${ }^{82}$ The CIE recommends calculating color difference $(\Delta \mathrm{E})$ based on CIELAB color parameters. The CIELAB is a non-linear transformation of the tristimulus space to agree with Munsell spacing and has been largely used to compare translucency among materials. ${ }^{83}$ A digital spectrophotometer (Gregtag Macbeth ${ }^{\circledR}$ Color-Eye 7000 A) was used to record the $\operatorname{CIELAB}\left(L^{*}, a^{*}, b^{*}\right)$ coordinates of all the ceramic samples. The TP of each specimen was obtained by calculating the color difference between the specimen against the white background and against the black background using the following equation:

$T P=\left\{(L b *-L W *)^{2}+(a b *-a w *)^{2}+(b b *-b W *)^{2}\right\}^{1 / 2}$

The mean values of translucency parameters (TP) for all groups has been graphically demonstrated in Figure 16, in Chapter 3. All treatments showed a slight reduction in the translucency parameter reading for the three ceramics, except that Group C (brushing only) for the IPS e.max demonstrated a slight increase in the translucency parameter as compared to Group A (control). It is well established that translucency of ceramics is affected by ceramic thickness and presence of opacifiers, such as tin oxide, more than by surface topography. The changes in 
translucency parameter in the current study are not significant statistically and although present, may not be visually perceptible to the naked eye.

\subsubsection{Color}

The subjectivity in perception of color by an observer results in variations and unpredictable differences in color evaluation and matching among clinicians. ${ }^{84}$ Spectral distribution of color stimulus, its size, shape and structure, surroundings of the stimulus, state of the observers visual system and the observer's experience affect the visual color evaluation. ${ }^{84}$ These elements can be clinically identified as change in ambient lighting, color of the patient's complexion, make up, clothing, distribution of the appearance of nearby teeth, and the contour and finish of the restoration. ${ }^{85}$

For the purpose of the study, a digital spectrophotometer (Gregtag Macbeth ${ }^{\circledR}$ Color-Eye $7000 \mathrm{~A})$ was used to record the CIELAB $\left(L^{*}, a^{*}, b^{*}\right)$ coordinates of all the ceramic samples. Color calculations were made using the $\mathrm{CIE} L^{*} a^{*} b^{*}$ readings in the following formula:

$$
\Delta E=\left(L^{\star 2}+a^{\star 2}+b^{\star 2}\right)^{1 / 2}
$$

In the current study, the color differences $(\Delta \mathrm{E})$ between groups were not statistically significant $(p<0.05)$ for the feldspathic porcelain and monolithic zirconia specimens. The IPS e.max ceramic specimens however, demonstrated statistical

differences as follows: There was a significant effect of acid and brushing treatment on color at the $p<0.05$ level for IPS e. $\max [F(3,28)=3.09, p=0.043$, 
$\left.\eta^{2}=0.25\right]$. We see a significant difference between the control group A vs. brush only group $\mathrm{C}$ [difference $=3.43,95 \% \mathrm{Cl}(0.19,5.67), p=0.035$ ]. Figure 15 in chapter 3 is a graphical demonstration of the differences in mean values of color for all groups of IPS e.max specimens. Additionally, Figure 19 demonstrates $L^{*}, a^{*}$ and $b^{*}$ readings for IPS e.max for different groups. All groups demonstrated an increase in $L^{*}$ readings with group $C$ (brush only) showing the largest increase with respect to the control group. The $L^{*}$ coordinate corresponds to the value (lightness or darkness) of an object which is considered to be the most important aspect of color selection in dentistry. The $a^{*}$ and $b^{*}$ readings were relatively constant between control, acid and brush groups but slightly increased for acid+brush group which indicates a shift from redness to greeness as the $a^{*}$ value increases. Similarly, the increase in $b^{*}$ represents a shift from yellowness to blueness. Figure 20 a-h., shows SEM micrographs of IPS e.max specimens after various treatments. It was observed that the ceramic surface exhibits a smoother appearance for groups C (brushing only) and D (acid + brushing treatment) as compared to the control group A. It may be extrapolated then, that the abrasive action of tooth-brushing could have potentially smoothened out some flaws in the surface of the ceramic material. This speculation, however, is not consistent with the surface roughness measurements made using a profilometer, where groups B though $D$ show a rougher surface (increased value of $R a$ in $\mu \mathrm{m}$ ) as compared to the control group. This observation opens up interesting avenues for discussion about the effect of a corrosive environment and tooth brushing on the color stability of IPS e.max. Although statistically significant differences were observed between 
groups, it has been accepted that a $\Delta \mathrm{E}$ value of 3.5 or greater is considered clinically significant. ${ }^{86}$ The groups closest to this value were the control group A and brush only group $C$, where the color difference $(\Delta E)$ was 3.54 . Whether these color changes are visually perceptible to the observer, can be further explored by more long term clinical studies.

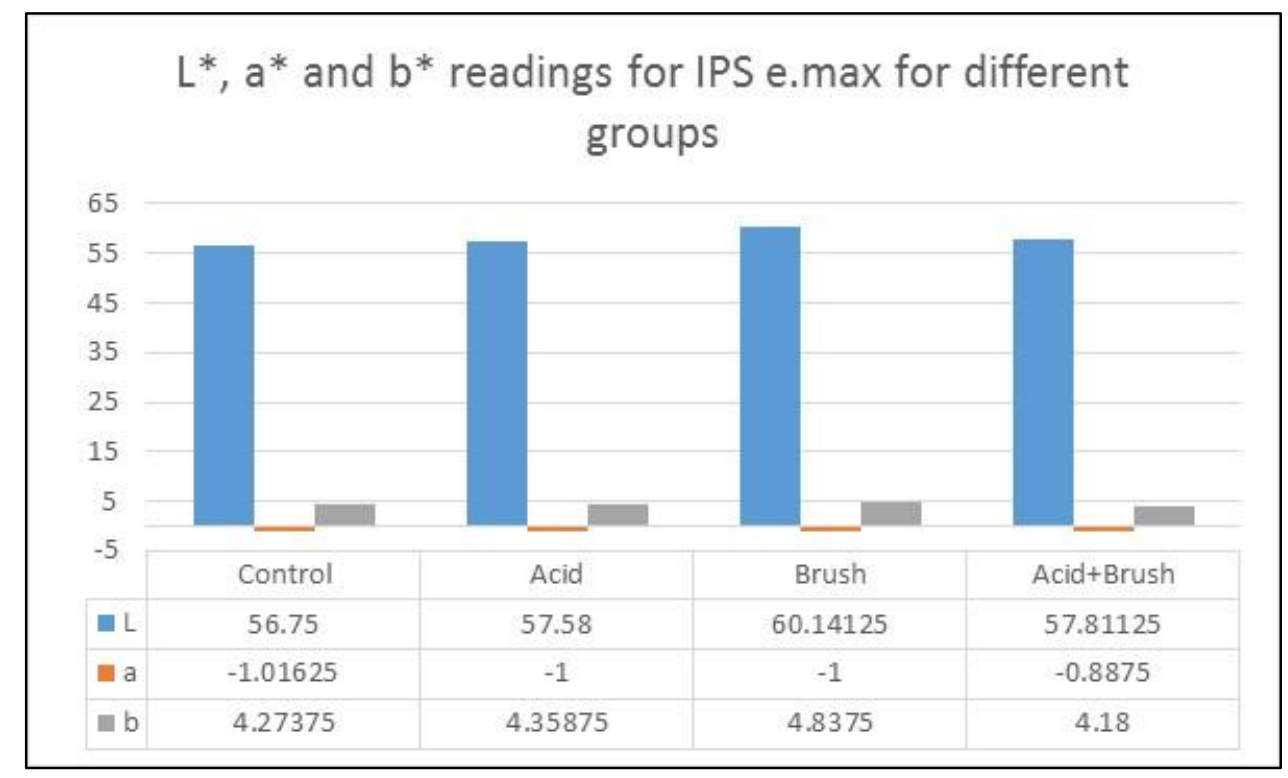

Figure 19. $L^{*}, a^{*}, b^{*}$ readings for IPS e.max for different groups

\subsubsection{Surface gloss}

The surface gloss is an important characteristic of a ceramic restoration. Attempts are made to obtain smooth, glossy surfaces for restorations to enhance esthetic appearance and to obtain surfaces which are unfavorable for plaque retention and wear of the opposing dentition. It has been established from previous studies that the various optical properties of a ceramic are a function of their composition, 
surface topography and thickness ${ }^{87}$, as these factors control light reflection and transmittance from the objects. Loss of luster or gloss can lead to a dull looking finish of the restoration and affect the visual color perception, having adverse effects on the esthetic outcome. Most ceramic restorations are glazed prior to insertion into the oral cavity. The goal of glazing is to seal the open pores in the surface via fired glass porcelain to render a smooth surface. ${ }^{88}$ However, some studies have suggested that a polished surface may be as acceptable as a glazed surface ${ }^{89}$ and preferred by ceramists for better control over the surface luster. For the purpose of this study, ceramics manufactured by CAD/CAM technology were obtained and heat treated per the recommendations of the manufacturer, without adding a glaze layer. The specimens were finished and polished as final restorations would be prepared by a technician for delivery to the clinician. A gloss meter (Novo-Curve ${ }^{\mathrm{TM}}$ Glossmeter, Rhopoint ${ }^{\mathrm{TM}}$ Instruments Ltd, Figure 12.a) was used to measure specular reflection gloss of all groups of ceramics. The surface gloss measurement was collected (in degrees) as the amount of reflected light at an equal but opposite angle to the projecting beam of light from the specimen. (Figure 12.b).

Figure 14 shows a graphically the differences in mean values of surface gloss for all groups of ceramic specimens. There was a significant effect of acid and brushing treatment on gloss at the $p<0.05$ level for feldspathic porcelain $[F(3,28)$ $\left.=4.25, p=0.013, \eta^{2}=0.31\right]$. We see a significant difference between the control group A vs. acid only group B [difference $=18.21,95 \% \mathrm{Cl}(3.45,32.96), p=0.011$ ] 
These findings are correlated with the changes in surface roughness ( $R a$ in $\mu \mathrm{m})$ of porcelain specimens (Figure 17). Increase in surface roughness caused the surface gloss to decrease. For groups $C$ and $D$ of the porcelain specimens, it is interesting to note that the increase in surface roughness and decrease in surface

gloss is not as significant. This may lead to the speculation that the brushing treatment had a tendency to smooth or seal the surface flaws created by the acid treatment, and this can further be explored in subsequent studies. Of the three materials chosen for this study, feldspathic porcelain is the softest material, which explain why the changes in surface roughness were the most noteworthy in these specimens.

\subsubsection{Study design}

To date, there is no consensus in the dental literature as to the method of gastric acid simulation and exposure time for an in-vitro study model. The ISO testing standard $^{90}$ for dental ceramics for solubility testing recommends the use of $4 \%$ acetic acid for $16 \mathrm{~h}$ at $80^{\circ} \mathrm{C}$, which corresponds to an in-vivo relevance of 2 years, based on the work of De Rijk. ${ }^{91}$ Hunt andMcIntyre $(1985)^{92}$ developed a model to simulate in-vivo acid erosion of teeth which simulates about 2-3 years clinically. Kukiattrakoon et al immersed ceramics in acidic solutions for 168 hours, and found an increase in their surface roughness. ${ }^{54}$ These studies, however, aged the specimens and subjected them to a static exposure to corrosive agents which is not clinically relevant. The novelty of the current study was to attempt to emulate 
the oral condition in patients with GERD or bulimia nervosa. With regards to exposure of teeth to acid, it has been observed in certain risk populations (subjects with eating disorders) that vomiting frequencies of $6-10$ times per day are often reported by patients. ${ }^{93}$ Based on this finding, some erosion-abrasion studies ${ }^{94-95}$ have used an erosion cycle of 6 times a day for 2 minutes each for 9 days. These studies were used for enamel and dentine, where the authors studied the demineralization-remineralization process upon acid exposure. The demineralization (acid attack) period of 2 minutes imitated the length of the $\mathrm{pH}$ decline in saliva after an acid attack. ${ }^{96-97}$ Additionally, the specimens were immersed in artificial saliva for 2 hours after every 2 minutes of exposure for the remineralization to occur. This is extrapolated as 108 minutes of acid attack and a total 108 hours of exposure. This was the treatment time adopted for the current study. It was assumed by the authors that immersion of ceramics in artificial saliva for 2 hours after each acid attack will not alter the surface or structure of the ceramics (as opposed to enamel or dentin), and hence the samples were thoroughly rinsed for 2 minutes between acid attacks. The oral environment is a dynamic environment with changes in $\mathrm{pH}$ due to the buffering action of saliva, and to the current knowledge of the author, is the only study to have made an attempt to mimic a clinical scenario for acid treatment of dental ceramics.

The component of toothbrush abrasion was incorporated in this current study to try to emulate different clinical scenarios of patient with GERD to see if toothbrush abrasion alone or in combination with acid erosion negatively impacted the 
properties of ceramics. A standardized brushing machine was utilized (with a constant load of 400 grams) and the brushing duration per sample (100 seconds per day) was approximately that of average daily habits in which the time spent for a whole quadrant is estimated to be approximately 24 seconds. ${ }^{98}$

The addition of pepsin and acid preparations was carried out as per recommendations of the manufacturer and a $\mathrm{pH}$ of 2.0 was maintained for the exposure. Even though gastric acid is a highly acidic acid (ph 1.6), the slightly higher $\mathrm{pH}$ for the experiment accounts for the buffering action of salivary components in the oral cavity. 


\subsection{Morphological assessment of surface characteristics}

Figures 20-22 demonstrate SEM images of all treatment groups from randomly selected specimens of all three ceramic materials. The images displayed are of 500x and 5000x magnification.

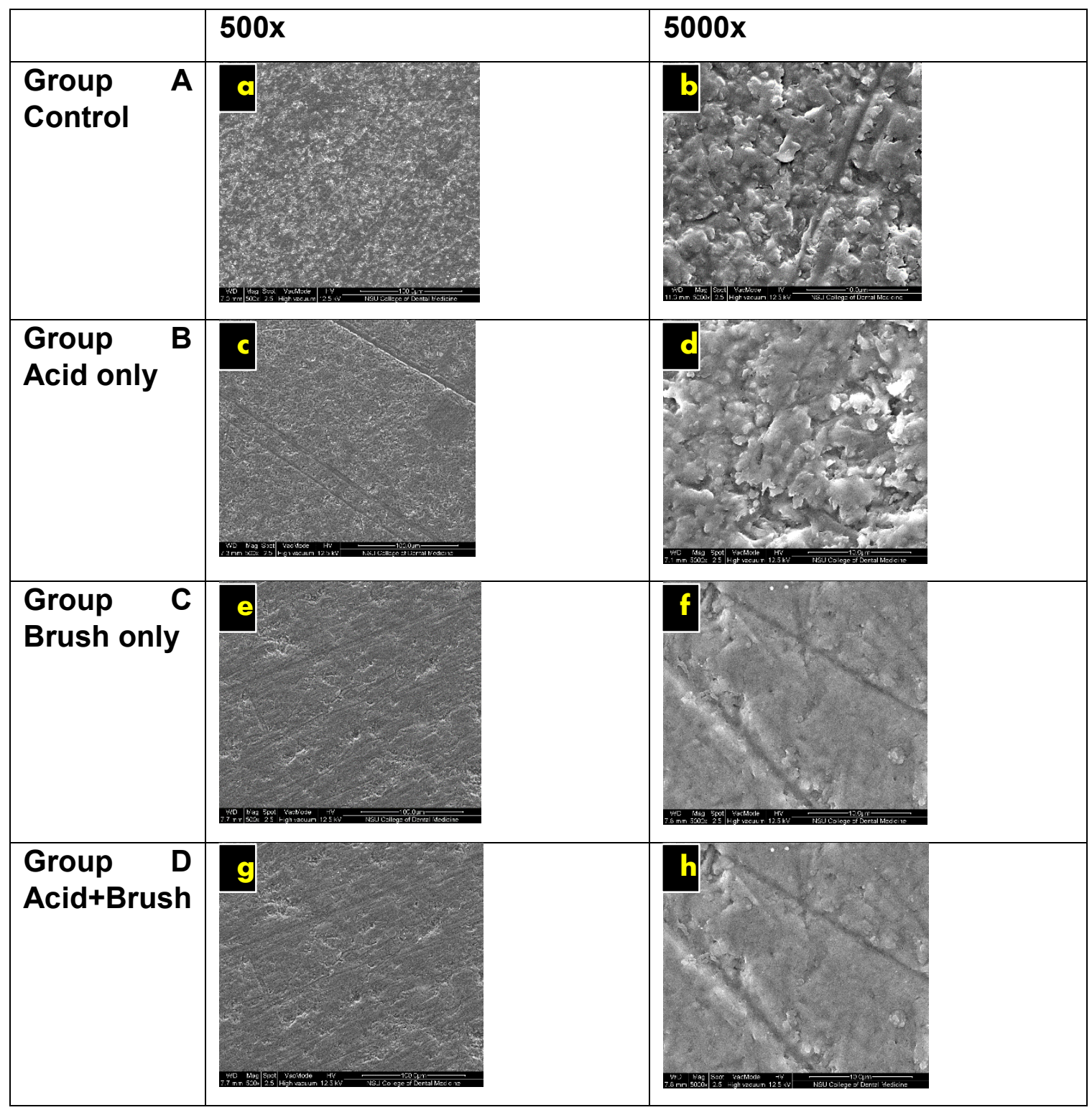

Figure 20. SEM micro graphs of IPS e.max samples of all groups 


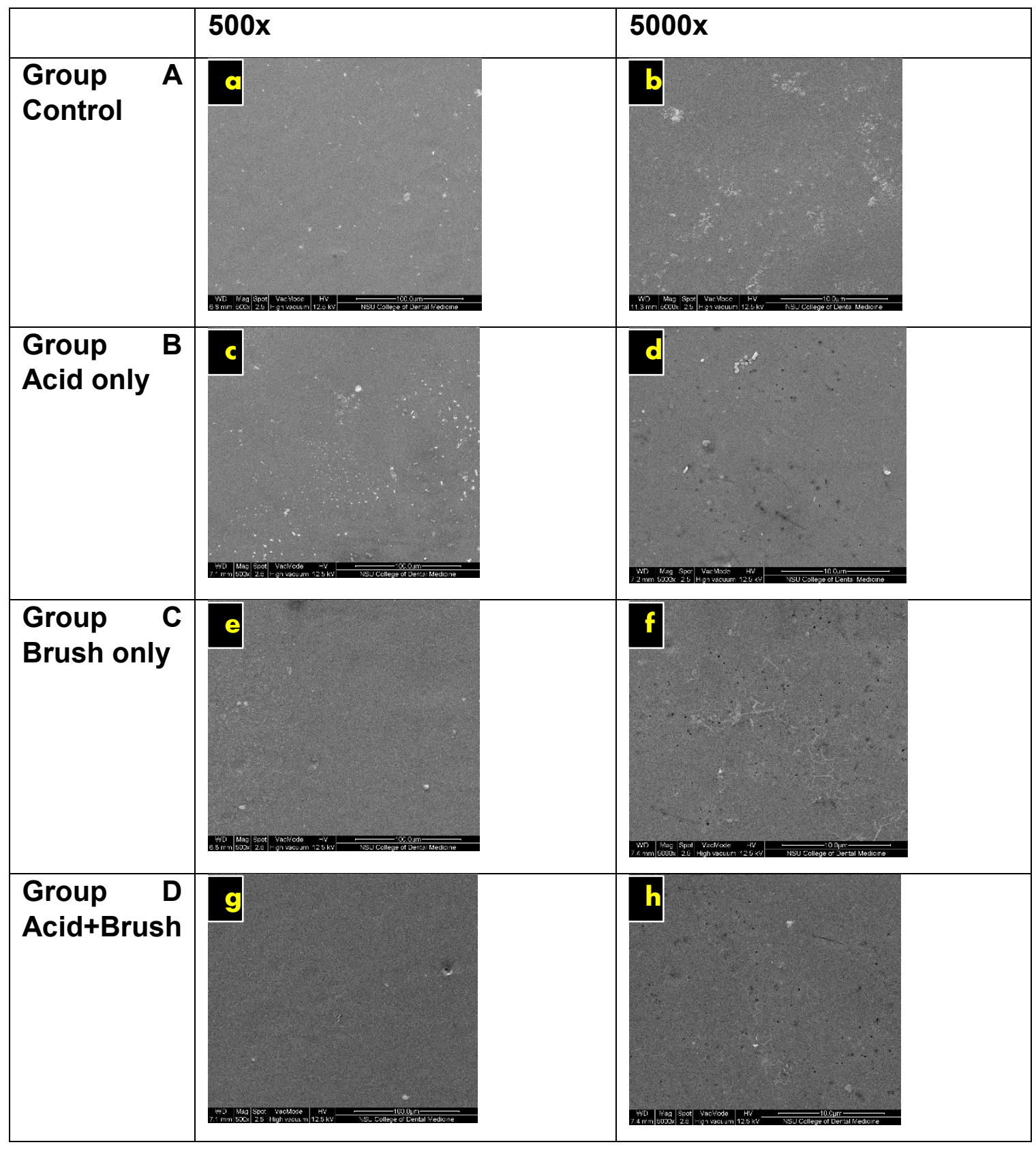

Figure 21. SEM micro graphs of Feldspathic porcelain samples of all groups 


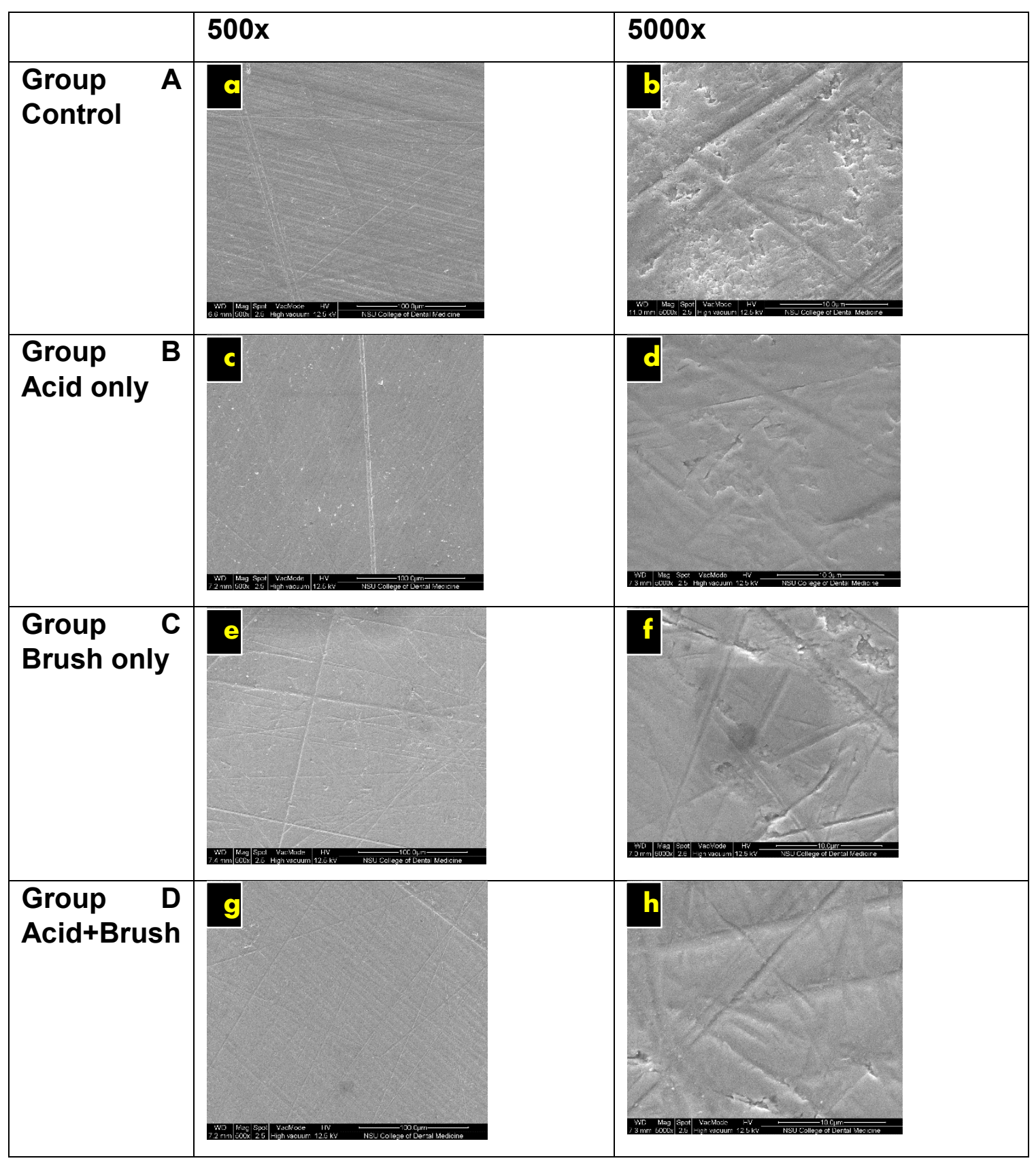

Figure 22. SEM micro graphs of Monolithic zirconia samples of all groups 


\subsection{Limitations, Implications and Future Studies}

The major limitations of this study is that it is an in-vitro study and was conducted in a non-blinded manner. It is well established that while in-vitro studies can simulate intra-oral conditions, it is not possible to fully reproduce them. When placed in the oral cavity, ceramic restorations are subject to complex thermal, physical and chemical challenges which are difficult to accurately reproduce under experimental conditions. The non-blinded methodology implemented for this research may have introduced confounding variables which could affect the outcome of the study. Although the ceramic samples were stored in distilled water 24 hours before and during the testing, an ideal environment should have been saliva. If the specimens are not sufficiently hydrated during testing, the effect of different treatments could vary.

Due to vast differences in the compositions of dental ceramics, and variations in testing protocols, previous research has shown conflicting findings about the effect of acid treatment on ceramics. While most results agree that surface roughness is negatively impacted by the acid treatment, a more standardized testing protocol is required for more reproducible results. This study measured the changes in surface roughness (in $\mu \mathrm{m}$ ). Wear resistance of the ceramics before and after acid attack was not evaluated. This can be calculated as the $\%$ weight loss from the specimen after acid treatment. This might give a better understanding of the potential of the acid attack to affect the resistance to abrasive wear of the ceramic. Another important concern is potential ion interactions and leaching upon corrosive attack, which can be explored in future research. 
An interesting finding of this research was the impact that the acid treatment, with and without the combination of toothbrush abrasion, had on the color of the IPS e.max ceramics. The brushing treatment produced a significant color difference as compared to the control $(\Delta E=3.54)$ and this incidental finding opens up avenues for further research on the color changes of these ceramics in the oral environment. 


\section{CHAPTER 5: CONCLUSIONS}

Within the limitations of this in-vitro experimental study, it was found that gastric acid treatment affected the surface roughness of all three ceramics used, where the changes for feldspathic porcelain were most significant, followed by lithium disilicate glass ceramics. The acid treatment with or without tooth brush abrasion negatively impacted the surface gloss of feldspathic porcelain and the color of IPS e.max, where color changes with brushing alone were most significant for IPS e.max specimens. The changes in translucency and mechanical strength for all materials were not statistically significant. Zirconia ceramic showed resistance to all treatments.

In conclusion, in the pursuit of the "latest and greatest" biomaterials, clinicians should always be aware of the potential longevity of any restorative material, especially when treating patients with comorbidities that alter the oral cavity environment. Further research should be carried out to confirm the findings of this present study in a reproducible manner to aid in proper material selection and more predictable treatment outcomes. 


\section{BIBLIOGRAPHY}

1. Hobkirk JA. Prosthodontics: A Past with a Future? J Can Dent Assoc. 2005 May; $71(5): 326$.

2. Kreulen CM, Van't Spijker A, Rodriguez JM, Bronkhorst EM, Creugers NH, Bartlett DW. Systematic review of the prevalence of tooth wear in children and adolescents. Caries Res 2010; 44:151-9.

3. Ganss C, Young A, Lussi A. Tooth wear and erosion: methodological issues in epidemiological and public health research and the future research agenda. Commun Dent Health 2011; 28:191-5.

4. SeemannR, FluryS, PfefferkornF, LussiA, NoackMJ.Restorative dentistry and res torative materials over the next 20 years: a Delphi survey. Dent Mater. 2014 Apr;30(4):442-8

5. D'Incau, Couture, Maureille. Human tooth wear in the past and the present: Tribological mechanisms, scoring systems, dental and skeletal compensations.Archivesoforalbiology 57(2012)214-229

6. Hunter J. The natural history of human teeth. Part 1. $2^{\text {nd }}$ ed. London: J. Johnson; 1778:39.

7. Verrett RG. Analyzing the Etiology of an Extremely Worn Dentition. J Prosthodont $2001 ; 10: 224-233$.

8. Glossary of Prosthodontic Terms, ed 7. J Prosthet Dent 1999;81:48

9. Turner KA, Missirlian DM. Restoration of the extremely worn dentition. J Prosthet Dent 1985; 52:467-74. 
10. Hattab FN, Yassin OM. Etiology and Diagnosis of Tooth Wear: A Literature Review and Presentation of Selected Cases. Int J Prosthodont 2000; 13:101-107.

11. Lambrechts P, Vanherle G, Vuylsteke M, Davidson GL. Quantitative evaluation of the wear resistance of posterior dental restorations: A new three-dimensional measuring technique. J Dent 1984; 12:252-267.

12. Grippo JO: Abfractions: A new classification of hard tissue lesions of teeth. J Esthet Dent 1991; 3:14-19.

13. Lee WC, Eakle WS: Stress-induced cervical lesions: Review of advances in past 10 years. J Prosthet Dent 1996; 75:487-494.

14. Shafer WG, Hine MK, Levy BM, et al: A Textbook of Oral Pathology $\left(4^{\text {th }}\right.$ Ed).Philadelphia, PA, Saunders, 1993:58-61.

15. Smith BGN, Bartlett DW, Robb ND. The prevalence, etiology and management of tooth wear in the United Kingdom. J Prosthet Dent 1997; 78:367-372.

16. Jarvinen V, Meurman JH, Hyvarinen I, Rytomaa H, Murtomaa H. Dental erosion and upper gastrointestinal disorders. Oral Surg Oral Med Oral Pathol 1988; 65:298-303.

17. Aine L, Baer N, Maki M. Dental erosions caused by gastroesophageal reflux disease in children. J Dent Child 1993;60: 210-214.

18. Gregory-Head, Curtis, Kim, Cello. Evaluation of dental erosion in patients with gastroesophageal reflux disease. J Prosthet Dent 2000;83:675-80.

19. Stege P, Visco-Dangler L, Rye L. Anorexia nervosa: Review including oral and dental manifestations. J Am Dent Assoc 1982; 104:648-652. 
20. Clark DC. Oral complications of anorexia nervosa and/or bulimia: With a review of the literature. J Oral Med 1985; 40:134-138.

21. Burke FJ, Bell TJ, Ismail N, Hartly P. Bulimia: Implications for the practising dentist. Br Dent J 1996; 180:421-426.

22. Harpenau, Noble, Kao. Diagnosis and Management of Dental Wear. Cda journal,39(4);224-28

23. Davis WB, Winter PJ, The effect of abrasion on enamel and dentine after exposure to dietary acid. Br Dent J 148(11-12- ):253-6, 1980.

24. Jaeggi T, Lussi A, Toothbrush abrasion of erosively altered enamel after intraoral exposure to saliva: an in situ study. Caries Res 33(6):455-61, 1999.

25. Barron, Carmichael, Marcon, Sàndor. Dental Erosion in Gastroesophageal Reflux Disease; J Can Dent Assoc 2003; 69(2):84-9.

26. Eccles JD, Jenkins WG. Dental erosion and diet. J Dent 1974; 2(4):153-9.

27. Sonnenberg A, El-Serag HB. Clinical Epidemiology and Natural History of Gastroesophageal Reflux Disease. Yale J Biol Med. 1999 Mar-Jun; 72(2-3):81-92.

28. Broliato et al. Esthetic and functional dental rehabilitation in a patient with gastroesophageal reflux. Quintessence Int 2008; 39:131-137.

29. Harrison's Principles of Internal Medicine. 16th Edition. 1742-44.

30. Uhlen, Tveit, Stenhagen, Mulic. Self-induced vomiting and dental erosion - a clinical study. BMC Oral Health 2014, 14:92

31. American Psychiatric Association: Diagnostic and Statistical Manual of Mental Disorders. Arlington, VA: American Psychiatric Association; 2013:329-354. 
32. Ganss C, Schlechtriemen M, Klimek J. Dental erosions in subjects living on a raw food diet. Caries Res 1999; 33: 74-80.

33. Ganss C, Hardt M, Blazek D, Klimek J, Schlueter N. Effects of toothbrushing force on the mineral content and demineralized organic matrix of eroded dentine. Eur $\mathrm{J}$ Oral Sci 2009; 117: 255-260.

34. Broliato et al. Esthetic and functional dental rehabilitation in a patient with gastroesophageal reflux. Quintessence Int 2008; 39:131-137.

35. Lazarchik, Filler. Effects of Gastroesophageal Reflux on the Oral Cavity. Am J Med. 1997; 103(5A):107-113.

36. Johansson AK, Norring C, Unell L, Johansson A: Eating disorders and oral health: a matched case-control study. Eur J Oral Sci2012, 120(1):61-68.

37. Barron, Carmichael, Marcon, Sàndor. Dental Erosion in Gastroesophageal Reflux Disease; J Can Dent Assoc 2003; 69(2):84-9.

38. Bartlett, Coward. Comparison of the erosive potential of gastric juice and a carbonated drink in vitro. J Oral Rehabil. 2001 Nov; 28(11):1045-7.

39. Burket's Oral Medicine, 11th Edition. 346-48

40. Kelly,Benetti. Ceramic materials in dentistry: historical evolution and current practice. Australian Dental Journal 2011; 56: 84-96.

41. Kelly. Dental Ceramics: Current thinking and trends. Dent Clin N Am 48 (2004) $513-530$.

42. Denry IL. Recent advances in ceramics for dentistry. Crit Rev Oral Biol Med 1996; 7: 134 . 
43. Kelly JR. Ceramics in restorative and prosthetic dentistry. Ann Rev Mater Sci 1997; 27: 443-68.

44. Giordano R. A comparison of all-ceramic restorative systems: part 2. Gen Dent 2000; 48: 38-40, 43-5.

45. Land CH. Porcelain dental art: No.II. Dent Cosmos 1903; 45:615-20.

46. McLean JW, Hughes TH. The reinforcement of dental porcelain with ceramic oxides. Br Dent J 1965; 119:251-67.

47. Sjogren G, Lantto R, Granberg A, Sund- strom BO, Tillberg A. Clinical examination of leucite-reinforced glass-ceramic crowns (Empress) in general practice: a retrospec-tive study. Int J Prosthodont 1999; 12:122- 8.

48. Conrad, Seong, Pesun. Current ceramic materials and systems with clinical recommendations: A systematic review. J Prosthet Dent 2007; 98:389-404.

49. Stappert CF, Att W, Gerds T, Strub JR. Fracture resistance of different partialcoverage ceramic molar restorations: An in vitro investigation. J Am Dent Assoc $2006 ; 137: 514-22$.

50. Manicone, lometti, Raffaeli. An overview of zirconia ceramics: Basic properties and clinical applications. Journal of dentistry 35 (2007) 819-826.

51. Piconi C, Maccauro G. Zirconia as a ceramic biomaterial. Biomaterials 1999; 20:125.

52. Della Bona, Kelly. The Clinical Success of All-Ceramic Restorations. J Am Dent Assoc. 2008 Sep; 139 Suppl: 8S-13S.

53. Raptis NV, Michalakis KX, Hirayama H. Optical behavior of current ceramic systems. Int J Periodontics Restorative Dent 2006; 26:31-41. 
54. Kukiattrakoon, Hengtrakool, Kedjarune-Leggat. Chemical durability and microhardness of dental ceramics immersed in acidic agents. Acta Odontologica Scandinavica, 2010; 68: 1-10.

55. Esquivel-Upshaw, Dieng, Clark, Neal, Anusavice. Surface Degradation of Dental Ceramics as a Function of Environmental pH. J Dent Res 92(5):467-471, 2013

56. Anusavice. Degradability of Dental Ceramics. Adv Dent Res. 1992 Sep; 6:82-9.

57. Drummond, Thompson, Super. Fracture surface examination of dental ceramics using fractal analysis. Dent Mater. 2005 Jun; 21(6):586-9.

58. Pinto, Cesar, Rosa, Yoshimura. Influence of $\mathrm{pH}$ on slow crack growth of dental porcelains. Dent Mater. 2008 Jun; 24(6):814-23.

59. Matsou, Vouroutzis, Kontonasaki, Paraskevopoulos, Koidis . Investigation of the influence of gastric acid on the surface roughness of ceramic materials of metalceramic restorations. An in vitro study. International Journal of Prosthodontics $2011 ; 24: 26-9$.

60. Al-Hiyasat AS, Saunders WP, Sharkey SW, Smith GM. The effect of a carbonated beverage on the wear of human enamel and dental ceramics. Journal of Prosthodontics 1998; 7:2-12.

61. Sulaiman TA, Abdulmajeed AA, Shahramian K, Hupa L, Donovan TE, Vallittu P, Närhi TO. Impact of gastric acidic challenge on surface topography and optical properties of monolithic zirconia. Dent Mater. 2015 Dec;31(12):1445-52

62. Ganss, Hardt, Blazek, Klimek, Schlueter.Effects of toothbrushing force on the mineral content and demineralized organic matrix of eroded dentine. Eur $\mathrm{J}$ Oral Sci. 2009 Jun; 117(3):255-60. 
63. Schlueter, Ganss, Hardt, Schegietz, Klimek.

Effect of pepsin on erosive tissue loss and

the efficacy of fluoridation measures in dentine in vitro. Acta Odontol Scand. 2007

Oct; 65(5):298-305.

64. Fuzzi M, Zaccheroni Z, Vallania G. Scanning electron microscopy and profilometer evaluation of glazed and polished dental porcelain. Int J Prosthodont. 1996; 9(5):452-8.

65. Schlissel ER, Newitter DA, Renner RR, Gwinnett AJ. An evaluation of postadjustment polishing techniques for porcelain denture teeth. J Prosthet Dent. 1980; 43(3):258-65.

66. Sarikaya I, Güler AU. Effects of different polishing techniques on the surface roughness of dental porcelains. J Appl Oral Sci. 2010 Jan-Feb; 18(1):10-6.

67. ASTM. F394-78: Standard test method for biaxial flexural strength (modulus of rupture) of ceramic substrates. 1996:1-5.

68. International Organization for Standardization. ISO 6872:1995, Dental ceramic. Geneva: ISO; 1995.

69. Yilmaz H, Aydin C, Gul BE. Flexural strength and fracture toughness of dental core ceramics. J Prosthet Dent. 2007 Aug; 98(2):120-8.

70. Ban S, Anusavice KJ. Influence of test method on the failure stress of brittle dental materials. J Dent Res 1990; 69:1791-9. 
71.Bagheri, Hooshmand, Aghajani. Effect of Ceramic Surface Treatments after Machine Grinding on the Biaxial Flexural Strength of Different CAD/CAM Dental Ceramics. J Dent (Tehran). 2015 Sep; 12(9): 621-629.

72.Zeng K, Oden A, Rowcliffe D. Flexure tests on dental ceramics. Int J Prosthodont 1996; 9:434-9.

73. Jemt T, Karlsson S, Hedegard B. Mandibular movement of young adults recorded by intraorally placed light-emitting diodes. J Prosthet Dent 1979; 42:669-73.

74. Ferrario VF, Sforza C, Zanotti G, Tartaglia GM. Maximal bite forces in healthy young adults as predicted by surface electromyography. J Dent 2004; 32:451-7.

75. Mijoska A, Popovska M. Evaluation of different in vitro testing methods for mechanical properties of veneer ceramics. Pril (Makedon Akad Nauk Umet Odd Med Nauki). 2015; 36(1):225-30.

76. Borges GA1, Sophr AM, de Goes MF, Sobrinho LC, Chan DC. Effect of etching and airborne particle abrasion on the microstructure of different dental ceramics. $\mathrm{J}$ Prosthet Dent. 2003 May; 89(5):479-88.

77. Zhang Y1, Lawn BR, Rekow ED, Thompson VP. Effect of sandblasting on the longterm performance of dental ceramics. J Biomed Mater Res B Appl Biomater. 2004 Nov 15; 71(2):381-6.

78. Geis Gerstorfer J, P. Fässler. Studies on fatigue behavior the dental ceramics zirconia TZP and In-Ceram. Dtsch Zahnarztl. 1999 54: 692-694.

79. Fondriest. Shade Matching in Restorative Dentistry: The Science and Strategies. Int J Periodontics Restorative Dent 2003; 23:467-479. 
80. Russell MD, Gulfraz M, Moss BW. In vivo measurement of colour changes in natural teeth. J Oral Rehabil. 2000 Sep; 27(9):786-92.

81. Brodbelt RH, O'Brien WJ, Fan PL, Frazer-Dib JG, Yu R. Translucency of human dental enamel. J Dent Res. 1981 Oct; 60(10):1749-53.

82. Johnston WM, Ma T, Kienle $\mathrm{BH}$. Translucency parameter of colorants for maxillofacial prostheses. Int J Prosthodont. 1995 Jan-Feb; 8(1):79-86.

83. Paravina RD, Ontiveros JC, Powers JM. Accelerated aging effects on color and translucency of bleaching-shade composites. J Esthet Restor Dent. 2004;16(2):117-26; discussion 126-7.

84. Ishikawa-Nagai S, Yoshida A, Sakai M, Kristiansen J, Da Silva JD. Clinical evaluation of perceptibility of color differences between natural teeth and allceramic crowns. J Dent. 2009; 37 Suppl 1:e57-63. doi: 10.1016/j.jdent.2009.04.004. Epub 2009 Apr 18.

85. Johnston WM, Kao EC. Assessment of appearance match by visual observation and clinical colorimetry. J Dent Res. 1989 May; 68(5):819-22.

86. Karaagaclioglu L, Terzioglu H, Yilmaz B, Yurdukoru B. In vivo and in vitro assessment of an intraoral dental colorimeter. J Prosthodont. 2010 Jun; 19(4):27985.

87.Dozić A, Kleverlaan CJ, Meegdes M, van der Zel J, Feilzer AJ. The influence of porcelain layer thickness on the final shade of ceramic restorations. J Prosthet Dent. 2003 Dec; 90(6):563-70. 88. Al-Wahadni A, Martin DM. Glazing and finishing dental porcelain: a literature review. J Can Dent Assoc. 1998 Sep; 64(8):580-3. 
89. Wiley MG. Effects of porcelain on occluding surface of restored teeth. J Prosthet Dent1989; 61:133-7.

90. International Standards for Dental Ceramics. ISO 6872. Geneva, Switzerland: International Organization for Standardization; 1995.

91. De Rijk WG, Jennings KA, Menis DL. A comparison of chemical durability test solutions for dental porcelains. In: Sauer BW, editor. Biomechanical engineeringrecent developments. Proceedings of biomedical engineering conference. PergamonPL New York, NY; 1985. P. 152

92. Hunt D, Mclntyre J. The development of an in vitro model of dental erosion. J Dent Res 1992; 71:985.

93. Ganss C, Schlechtriemen M, Klimek J. Dental erosions in subjects living on a raw food diet. Caries Res 1999; 33: 74-80.

94. Ganss C, Hardt M, Blazek D, Klimek J, Schlueter N. Effects of toothbrushing force on the mineral content and demineralized organic matrix of eroded dentine. Eur $\mathrm{J}$ Oral Sci 2009; 117: 255-260.

95. Schlueter N, Ganss $\quad$ C, Hardt $\quad$ M, Schegietz $\quad$ D, Klimek J.Effect of pepsin on erosive tissue loss and the efficacy of fluoridation measures in dentine in vitro. Acta Odontol Scand. 2007 Oct; 65(5):298-305.

96. Meurman JH, Rytomaa I, Kari K, Laakso T, Murtomaa H. Salivary pH and glucose after consuming various beverages, including sugar-containing drinks. Caries Res 1987; / 21: / 353-9. 
97. Imfeld TN. Identification of low caries risk dietary components. Basel: Karger; 1983.

98. Ganss C, Schlueter N, Preiss S, Klimek J. Tooth brushing habits in uninstructed adults - frequency, technique, duration, and force. Clin Oral Investig. 2009 Jun; 13(2):203-8. 